\title{
HydroBlocks v0.2: enabling a field-scale two-way coupling between the land surface and river networks in Earth system models
}

\author{
Nathaniel W. Chaney ${ }^{1}$, Laura Torres-Rojas ${ }^{1}$, Noemi Vergopolan ${ }^{2}$, and Colby K. Fisher ${ }^{3}$ \\ ${ }^{1}$ Department of Civil and Environmental Engineering, Duke University, Durham, NC, USA \\ ${ }^{2}$ Department of Civil and Environmental Engineering, Princeton University, Princeton, NJ, USA \\ ${ }^{3}$ Princeton Climate Analytics, Princeton University, Princeton, NJ, USA
}

Correspondence: Nathaniel W. Chaney (nathaniel.chaney@duke.edu)

Received: 27 August 2020 - Discussion started: 28 October 2020

Revised: 14 September 2021 - Accepted: 23 September 2021 - Published: 9 November 2021

\begin{abstract}
Over the past decade, there has been appreciable progress towards modeling the water, energy, and carbon cycles at field scales $(10-100 \mathrm{~m})$ over continental to global extents in Earth system models (ESMs). One such approach, named HydroBlocks, accomplishes this task while maintaining computational efficiency via Hydrologic Response Units (HRUs), more commonly known as "tiles" in ESMs. In HydroBlocks, these HRUs are learned via a hierarchical clustering approach from available global high-resolution environmental data. However, until now there has yet to be a river routing approach that is able to leverage HydroBlocks' approach to modeling field-scale heterogeneity; bridging this gap will make it possible to more formally include riparian zone dynamics, irrigation from surface water, and interactive floodplains in the model. This paper introduces a novel dynamic river routing scheme in HydroBlocks that is intertwined with the modeled field-scale land surface heterogeneity. Each macroscale polygon (a generalization of the concept of macroscale grid cell) is assigned its own fine-scale river network that is derived from very high resolution $(\sim 30 \mathrm{~m})$ digital elevation models (DEMs); the inlet-outlet reaches of a domain's macroscale polygons are then linked to assemble a full domain's river network. The river dynamics are solved at the reach-level via the kinematic wave assumption of the Saint-Venant equations. Finally, a two-way coupling between each HRU and its corresponding fine-scale river reaches is established. To implement and test the novel approach, a $1.0^{\circ}$ bounding box surrounding the Atmospheric Radiation and Measurement (ARM) Southern Great Plains (SGP) site in northern Oklahoma (United States) is used. The results show (1) the implementation of the two-way coupling be-
\end{abstract}

tween the land surface and the river network leads to appreciable differences in the simulated spatial heterogeneity of the surface energy balance, (2) a limited number of HRUs $\left(\sim 300\right.$ per $0.25^{\circ}$ cell) are required to approximate the fully distributed simulation adequately, and (3) the surface energy balance partitioning is sensitive to the river routing model parameters. The resulting routing scheme provides an effective and efficient path forward to enable a two-way coupling between the high-resolution river networks and state-of-the-art tiling schemes in ESMs.

\section{Introduction}

Recent years have seen a renewed effort to improve the representation of land surface heterogeneity in Earth system models (ESMs) (Chaney et al., 2018; Newman et al., 2014; Clark et al., 2015b; Fan et al., 2019). This effort is driven in part by the limitations of existing upscaling parameterizations to adequately simulate the multi-scale interactions between the water, energy, and carbon cycles (Wood et al., 2011; Bierkens et al., 2014). Although the desired goal might eventually be a modeling approach that models every meter-scale grid cell over the globe, for the foreseeable future the significant computational barriers will continue to limit the feasibility of this approach. This is especially true given the need for largeensemble frameworks to handle the significant structural and parameter uncertainties that emerge in models when moving to very high spatial resolutions over large spatial extents (Beven et al., 2015). As a result, there is a persistent need to use reduced-order modeling approaches that are able to con- 
verge on the desired meter-scale modeling while minimizing computational expense.

One approach widely adopted over the past decades to represent the landscape heterogeneity within Earth system models (ESMs) is the use of "tiling" schemes, which effectively partition a macroscale grid cell into representative clusters (e.g., forests, grasslands, etc.). This concept is similar to the concept of hydrologic response units (HRUs) in hydrologic models. Since their origin in the late 1980s and early 1990s (Avissar and Pielke, 1989; Koster and Suarez, 1992), tiling schemes have moved to include spatial variability in land use, soil type, elevation gradients, and management practices, among others. Chaney et al. (2016b) and Newman et al. (2014) take this a step further by designing a mechanism to derive these tiles or HRUs by clustering available spatial environmental datasets of the drivers of landscape heterogeneity. Furthermore, over the past decade, there has been an effort to adapt these tiling schemes to enable hillslopescale processes (e.g., lateral flow) via Darcy flow along topographic gradients within a grid cell (Clark et al., 2015b; Fan et al., 2019; Chaney et al., 2018; Subin et al., 2014; Swenson et al., 2019). These additions are making it possible for ESMs to simulate the role of local lateral flow along topographic gradients, which has implications for modeling the riparian ecosystems and surface energy balance partitioning. However, the two-way interconnectivity between the modeled hillslopes and their respective channels has yet to be explored.

In parallel to the development of state-of-the-art tiling schemes, there has been significant innovation in river routing schemes within ESMs in recent years. For a comprehensive review of the advances in macroscale routing schemes the reader is referred to Shaad and Di Baldassarre (2018); a brief overview of these advances is provided here. Early developments in these schemes focused on the horizontal transfer time and integration of runoff over the land surface, allowing for the validation of early land surface model (LSM) outputs against streamflow observations. This initial work is embodied in the Impulse Response Function Unit Hydrograph (IRF-UH) approach described in Lohmann et al. (1996), which represented the process as linear and timeinvariant, both in grid cells and between grid cells in the river network. Alternative approaches were proposed, focusing instead on storage-based schemes to represent the spatial distribution of flow. The Total Runoff Integration Pathways (TRIP) model presented by Oki and Sud (1998) was the first to use a simplified form of the 1D kinematic wave routing equation with a constant velocity for water movement between grid cells, an approach that has since been implemented in many LSMs over varying scales of global river networks (Pappenberger et al., 2010). With recent computational and data advances, these basic models have been expanded to better utilize the outputs of general ESMs for global predictions beyond just discharge. For example, the recent MizuRoute model (Mizukami et al., 2016) builds upon the approaches described above. MizuRoute combines both approaches to model the flow from hillslope to channels through a gamma-distribution-based IRF-UH, while the main channel routing is performed using either a kinematic wave approximation or a linear IRF-UH method, enabling the use of higher-resolution terrain and network data with relatively coarse ESM outputs. Alternative approaches for using high-resolution vector river networks have been proposed, such as the Routing Application for Parallel Computation of Discharge model (RAPID). RAPID leverages advances in high-performance computing to create a highly efficient vector river routing scheme that uses a matrix-based version of the Muskingum-Cunge method (David et al., 2016, 2011).

Recent macroscale routing model development has sought to make use of advances in data and computational resources to further enable integrations with ESMs. The Model for Scale Adaptive River Transport (MOSART; Li et al., 2013), a recent example of this, divides a grid cell into hillslopes, tributaries, and a main channel to solve the flow of water through the river network via the kinematic wave approximation of the Saint-Venant equations. This decoupling of the ESM grid from that of the routing model (network) allows for differences in scale to more accurately capture flow and channel dynamics at any point within a given watershed. Other models have attempted to move beyond the more simplistic representations of flow hydrodynamics to better represent flood inundation. A recent example of this is the Catchment-based Macro-scale Floodplain model (CaMa-Flood) (Yamazaki et al., 2011), which discretizes the grid cells into unit catchments and explicitly parameterizes the topography of the floodplain for each unit. CaMA-Flood then simulates open channel flow via the local inertial equation, a simplified form of the full 1D Saint-Venant equation, allowing for an estimation of water depth and area of inundation in ESM grid cells.

Although there have been significant advances in river routing and tiling schemes over the past decade, there has yet to be a concerted effort to couple these two concepts in ESMs. This persistent lack of interconnectivity between the modeled river network and the land surface leads to (1) oversimplified sub-grid river networks (e.g., tributaries are mostly ignored) (Jones and Schmidt, 2017; Swanson and Meyer, 2014; Rice, 2017), (2) a lack of interaction between the land surface tiles and the river networks (e.g., simulated flooding of the Nile River does not recharge the land surface) (Shen et al., 2016; Helton et al., 2012; Bisht et al., 2017), (3) the water moving through the sub-grid river network not influencing the surface energy partitioning (i.e., macroscale schemes continue to mostly treat river networks as pipes) (Zampieri et al., 2011; Bisht et al., 2017; Sheng et al., 2017), and (4) local-scale irrigation and water management schemes being spatially agnostic and relying almost exclusively on the main channel (Shaad and Di Baldassarre, 2018; Voisin et al., 2017; Pokhrel et al., 2015). All these deficiencies compound to illustrate a persistent weakness in Earth system models by ignoring critical processes that are known to play an impor- 
tant role in both the natural and engineered hydrologic systems (Pokhrel et al., 2016; Fan et al., 2019). With the recent advances in both river routing and tiling schemes, the timing is right to enable two-way interactions between the tiling schemes and river networks in ESMs.

This study provides a path to address this persistent deficiency in ESMs. This is accomplished by implementing a reach-based routing model in the HydroBlocks land surface model (Chaney et al., 2016b) and enabling a two-way coupling with the modeled hydrologic response units. The primary features of the novel river routing scheme include (1) each macroscale polygon (a generalization of the concept of macroscale grid cell) being assigned its own fieldscale river network delineated from digital elevations models (DEMs), (2) the fine-scale inlet-outlet reaches of the macroscale polygons being linked to assemble the continental river networks (and to ensure conservation of mass), (3) river dynamics being solved at the reach-level via an implicit solution of the kinematic wave simplification of the Saint-Venant equations, and (4) a two-way coupling that is established between HRUs and the river network. The scheme is implemented over a $1.0^{\circ}$ bounding box around the Southern Great Plains site in northern Oklahoma in the United States. Furthermore, a series of experiments are performed to understand (1) the sensitivity of the land surface to the two-way coupling, (2) the number of HRUs that are required to approximate the fully distributed simulation adequately, and (3) the impact of the uncertainty in the routing scheme parameters in the macroscale response.

\section{Data and methods}

\subsection{Study domain}

A $1.0^{\circ}$ box in central northern Oklahoma and southern Kansas in the United States is used to implement and test the new routing scheme (see Fig. 1). The region is generally flat with a shallow decreasing gradient in terrain, precipitation, and normalized difference vegetation index (NDVI) from west to east. The overall climate is typically dry, with cold winters and hot summers. The Salt Fork Arkansas River, Chikaskia River, and to a lesser extent the Arkansas River traverse the region; all rivers in the domain eventually flow into the Arkansas River. The vegetation throughout the domain is primarily croplands with forested regions found along the riparian areas. There are also small urban areas dispersed throughout the region with the town of Enid in the southeast corner being the largest. This domain contains the Atmospheric Radiation and Measurement (ARM) Southern Great Plains central facility (SGP CF) among other ARM SGP facilities. As the largest climate facility in the world, ARM SGP collects a wealth of data on land-atmosphere interactions and atmospheric processes that are used frequently to evaluate and improve sub-grid atmospheric processes in
ESMs. Understanding the role that the interconnected land surface and river network play in the partitioning of the surface energy balance (and its role in land-atmosphere interactions) is a primary motivation for using this domain in this study.

\subsection{Land surface model: HydroBlocks}

HydroBlocks is a field-scale resolving land surface model (Chaney et al., 2016b) that accounts for the water, energy, and carbon balance to solve land surface processes at high spatial and temporal resolutions. HydroBlocks leverages the repeating patterns that exist over the landscape (i.e., the spatial organization) by clustering areas of assumed similar hydrologic behavior into HRUs. The simulation of these HRUs and their spatial interactions allows the modeling of hydrological, geophysical, and biophysical processes at the field scale (e.g., $30 \mathrm{~m}$ ) over regional to continental extents (Chaney et al., 2016b; Vergopolan et al., 2020). The core of HydroBlocks is the Noah-MP vertical land surface scheme (Niu et al., 2011). HydroBlocks applies Noah-MP in an HRU framework to explicitly represent the spatial heterogeneity of surface processes down to field scale. At each time step, the land surface scheme updates the hydrological states at each HRU, and the HRUs dynamically interact laterally via subsurface flow. In the original HydroBlocks, subsurface flow between HRUs was modeled via a subsurface kinematic wave. In this implementation, following the approach used in Chaney et al. (2018), the subsurface flow module has been updated by computing the Darcy flux between adjacent HRUs at each subsurface level. The fluxes are then included as divergence terms within their corresponding subsurface level of the vertical one-dimensional solution of Richards' equation in Noah-MP. This allows for the flow of water between HRUs to also be driven by capillarity and not just the predefined topographic gradient.

\subsection{Hierarchical generation of hydrologic response units}

The HRU generation scheme in the original HydroBlocks (Chaney et al., 2016b) was not sufficient to capture the dynamics in riparian zones (e.g., runoff), which led to the development of the hierarchical multivariate clustering (HMC) approach introduced in Chaney et al. (2018). This study builds on the 2018 version of HMC to enable adequate coupling of the land surface with the river network within HydroBlocks. HMC uses a field-scale map (e.g., $30 \mathrm{~m}$ ) of delineated watersheds and the corresponding DEM as building blocks to generate the HRUs. Prior to constructing the HRUs, following Chaney et al. (2018), the river network and watersheds are delineated from a $30 \mathrm{~m}$ DEM by first sink filling and then delineating the channels using an area threshold of $10000 \mathrm{~m}^{2}$. The $30 \mathrm{~m}$ channel pixels are then grouped by reach. The watersheds are assembled by finding all $30 \mathrm{~m}$ pixels that flow 


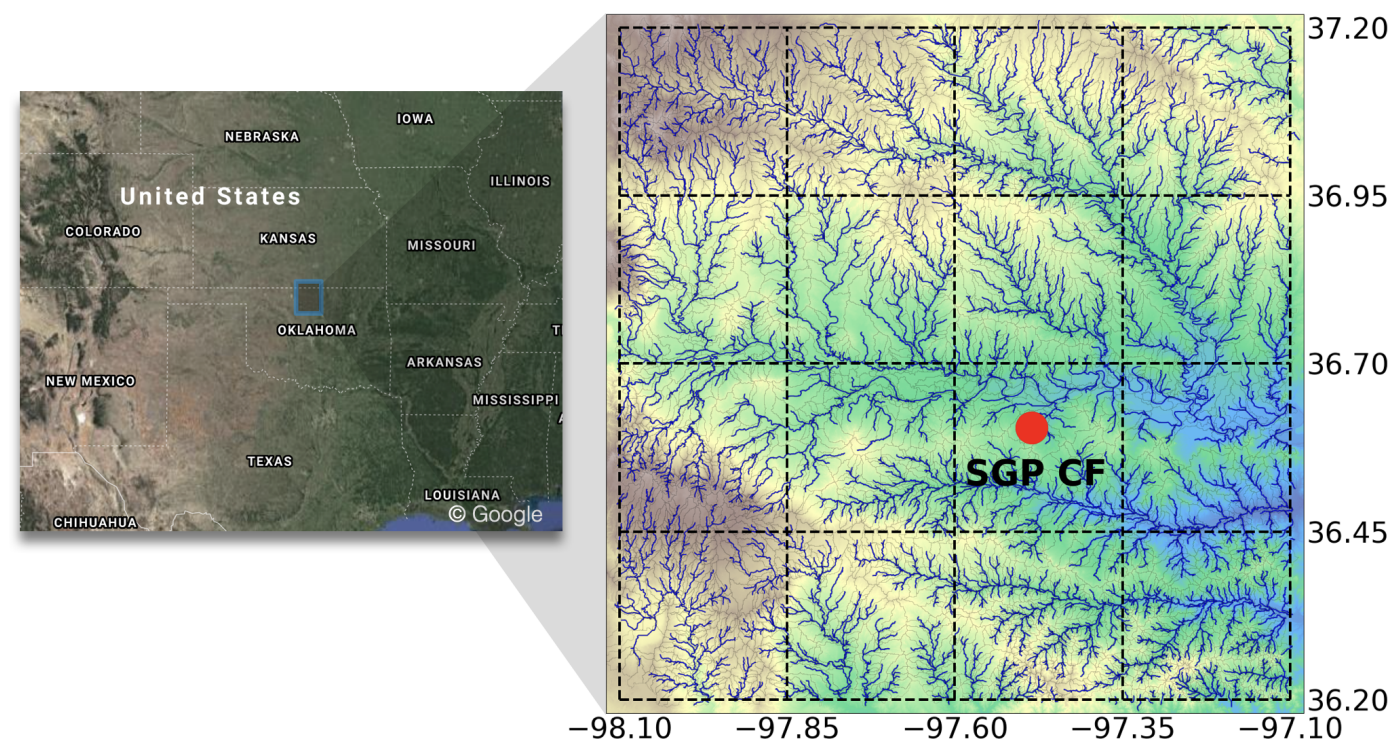

Figure 1. The study area consists of a $1.0^{\circ}$ box in central northern Oklahoma and southern Kansas. The domain contains the Atmospheric Radiation and Measurement (ARM) Southern Great Plains central facility (SGP CF).

into a given reach via steepest descent. The following steps are then taken to assemble the HRUs from these data.

1. Macroscale polygons. The large domain is partitioned into smaller subdomains defined in this study as macroscale polygons. A macroscale polygon is a generalization of the concept of a macroscale grid cell; it is analogous to a grouped response unit (GRU; Clark et al., 2015a). HMC is designed to handle any geometry of macroscale polygons; the only constraint is that a given delineated watershed cannot be split between polygons. This constraint precludes the use of a regular latitude-longitude macroscale grid. Instead, for this study, a 0.25 arc degree grid is modified to meet this constraint. To be more specific, the boundaries of each 0.25 arc degree grid cell are adjusted such that a watershed is assigned to the macroscale polygon where it has the majority of its area (see Fig. 2a for an example). Note that other domain decompositions are feasible under HMC's current architecture.

2. Clusters of watersheds. The watersheds contained within a given macroscale polygon are clustered using $K$ means. The feature predictors used in the clustering include latitude, longitude, flow accumulation area, and the natural logarithm of the flow accumulations area. Log-scale accumulation area was used to separate the low-order reaches from the high-order reaches, accumulation area was used to separate reaches within the large rivers, and latitude-longitude were used to represent location-driven differences in atmosphere forcing, land use, and soils, among others. Figure $2 b$ shows an example of this division for 10 clusters of watersheds
( $k$ ) of the macroscale polygons. After clustering the watersheds, to maximize similarity among the watersheds that are assigned to a given cluster of watersheds, the empirical cumulative distribution function (CDF) of the $30 \mathrm{~m}$ height above nearest drainage (HAND; Nobre et al., 2011) values within each watershed is matched to a representative watershed's HAND empirical CDF. The representative watershed's HAND empirical CDF of a cluster of watersheds is set to be the average of all of its watersheds' empirical CDFs (for a background on CDF matching, see Reichle and Koster, 2004). Note that the concept of a cluster of watersheds is only used for the non-routing component of HydroBlocks.

3. Height bands. The $30 \mathrm{~m}$ HAND values of each cluster of watersheds are discretized into height bands. First, all $30 \mathrm{~m}$ pixels that belong to the channels within a given cluster of watersheds are grouped into one height band. Following this, the non-channel $30 \mathrm{~m}$ pixels are discretized into additional height bands by binning HAND values. The binning involves assembling the smallest HAND values that have an areal coverage $n$ (user-defined) times larger than its adjacent lower height band. For example, the height band immediately above the channel height band will have an areal coverage $n$ times larger than the channel height band. The next height band will have an areal coverage $n^{2}$ larger than that of the channel and so forth. The described method is a simple yet robust approach to maximize spatial detail of height bands near riparian zones while coarsening upslope. Figure $2 \mathrm{c}$ shows the discretization into height bands of the watersheds that belong to the cluster of watersheds 1 of the macroscale polygon 7 in the domain. 
An additional $\operatorname{maxhb}$ parameter is used to ensure the number of height bands per cluster of watersheds does not exceed this user-defined threshold (maxhb is fixed at 100 in this study).

4. Intra-band clusters. To characterize the role of subheight band heterogeneity of land use, soils, and elevation, among others on water and energy states and fluxes, each height band within each cluster of watersheds is further divided into clusters (here called intraband clusters). This is accomplished by iterating per height band and clustering all the corresponding $30 \mathrm{~m}$ pixels. Given that the areal coverage of each height band can vary; the number of intra-band clusters per height band is set to be proportional to their fractional coverage of the cluster of watersheds. The user-defined $p$ parameter is the average number of clusters per height band. Figure $2 \mathrm{~d}$ shows an example of this division for $p=5$ using latitude, longitude, land cover, and clay as covariate features. The fractional coverage weight of $p$ compensates for the telescoping mesh of height bands produced by the parameter $n$. The smaller height bands next to the channel will have few intra-band clusters while the larger ones upslope will have many more.

The multi-level hierarchy of clusters of watersheds, height bands, and intra-band clusters leads to the definition of the hydrologic response units (HRUs) per macroscale polygon (Fig. 2e). In summary, each macroscale polygon is divided into $k$ clusters of watersheds. A given cluster of watersheds groups together several reaches (one reach per watershed). Note that this clustering of watersheds is only used in the non-routing components of HydroBlocks; each reach maintains its unique properties in the routing scheme. All watersheds that belong to a given cluster of watersheds are split first into height bands (defined by $n$ and maxhb) and then intra-band clusters $(p)$. The coupling between the land surface and routing modules handles the interaction between clusters of watersheds and the simulated reaches.

\subsection{River routing scheme}

The river routing scheme implemented within HydroBlocks is a reach-based implicit solution of the Saint-Venant equations with the kinematic wave assumption. The conservation of mass across a 1D reach is given by

$\frac{\partial A}{\partial t}=\frac{\partial Q}{\partial x}+S$,

where $\frac{\partial A}{\partial t}$ is the change in the cross-sectional area of the flow with respect to time $\left[\frac{L^{2}}{T}\right], \frac{\partial Q}{\partial x}$ is the change in discharge across an infinitesimally small reach length (note that $Q=u A$ where $u$ is the velocity of the flow), and $S$ is a source-sink term of the cross-sectional area. Following the kinematic wave assumption, uniform flow is assumed (i.e., $s_{0}=s_{\mathrm{f}}$ ), and thus $u$ can be estimated at each time step for a given reach via Manning's equation:

$u=\frac{1}{n} R_{\mathrm{h}}^{\frac{2}{3}} S_{0}^{\frac{1}{2}}$,

where $n$ is Manning's coefficient, $R_{\mathrm{h}}$ is the hydraulic radius, and $S_{0}$ is the slope of a given reach. Note that the hydraulic radius is given by $R_{\mathrm{h}}=\frac{A}{P}$, where $P$ is the wetted perimeter. For this implementation, a compound channel composed of a rectangular channel and a symmetric floodplain is assumed (see Fig. 3). The segmented conveyance method is used where the conveyance of both channel (c) and floodplain (f) components are summed, and the effective velocity for the compound channel is computed as follows:

$u=\frac{S_{0}^{\frac{1}{2}}}{A}\left(\frac{1}{n_{\mathrm{c}}} A_{\mathrm{c}} R_{\mathrm{h}, \mathrm{c}}^{\frac{2}{3}}+\frac{1}{n_{\mathrm{f}}} A_{\mathrm{f}} R_{\mathrm{h}, \mathrm{f}}^{\frac{2}{3}}\right)$.

As shown in Fig. 3, each reach's cross-sectional profile is composed of a rectangular channel and a symmetric floodplain that is learned from the reach's discretized height bands (computed in Sect. 2.3). At each reach, the cross-sectional area of the flow and the derived cross-sectional profile are used to determine the wetted perimeters $P_{\mathrm{c}}$ and $P_{\mathrm{f}}$ and the cross-sectional areas $A_{\mathrm{c}}$ and $A_{\mathrm{f}}$ at each time step.

To solve the Saint-Venant equation with the kinematic wave assumption at each time step, a fully implicit first-order finite-volume upwind scheme in space and backward Euler in time is used:

$$
\frac{A_{i}^{n+1}-A_{i}^{n}}{\Delta t}=\frac{Q_{i+1}^{n+1}-Q_{i}^{n+1}}{\Delta x}+S,
$$

where the upstream $Q_{i+1}^{n+1}$ contribution to a given reach is the sum of the discharge of all the reaches that are immediately upstream of a given reach $\left(Q_{i+1}^{n+1}=\sum_{j} u_{j}^{n+1} A_{j}^{n+1}\right)$. In other words, the upstream internal boundary of reach $i$ is the sum of the discharge of all reaches $j$ that flow into reach $i$ (Jacovkis and Tabak, 1996). Note that $\Delta x$ is the length of a given reach in the network and will rarely be the same across reaches. $S$ is a source-sink term that can account for inflow from runoff, as well as water abstractions from irrigation and recharge of the land surface. This leads to a system of nonlinear equations (per macroscale polygon) to be solved per time step. Given the nonlinearities in the hydraulic radius calculation, as well as the need to iteratively exchange network boundary conditions between macroscale polygons, an iterative time step is implemented. In the current implementation, a Picard iteration is used to attempt convergence at each time step.

Similar to Mizukami et al. (2016), an impulse response function is used to route the runoff produced at the HRU level in HydroBlocks to its corresponding channel. HydroBlocks' HRU delineation is first used to assemble a histogram of travel times (constant velocity of the flow per grid cell) of 
(a) Macroscale polygons

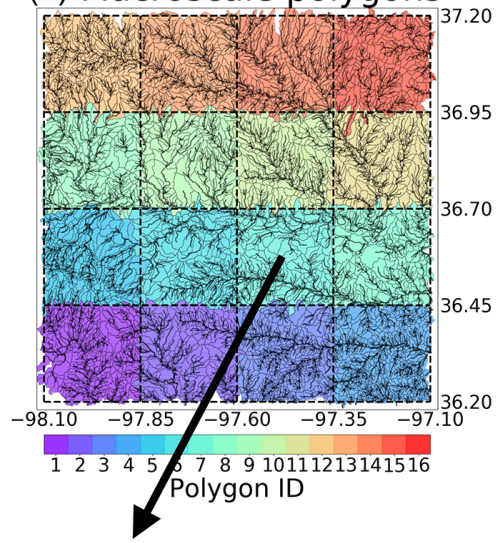

(e) Hydrologic Response Units

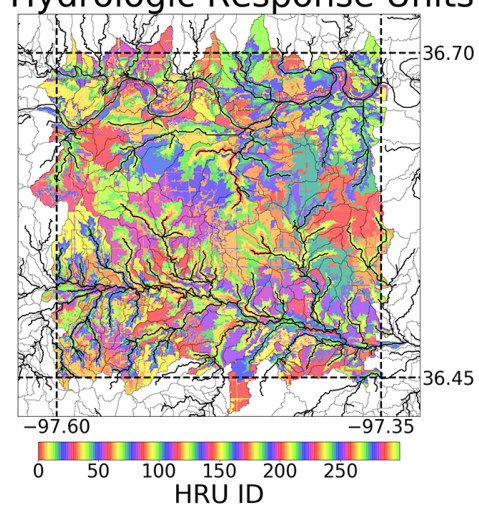

(b) Clusters of watersheds

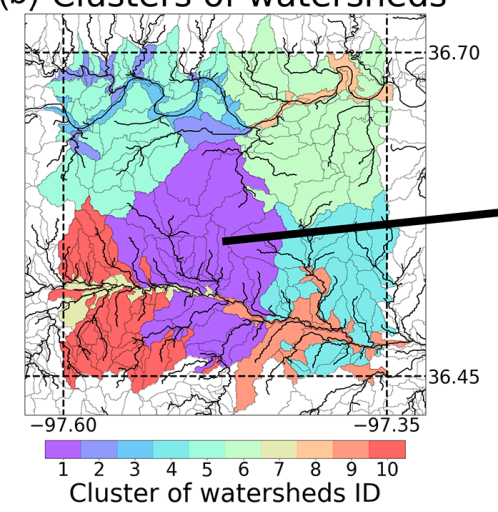

(c) Height bands

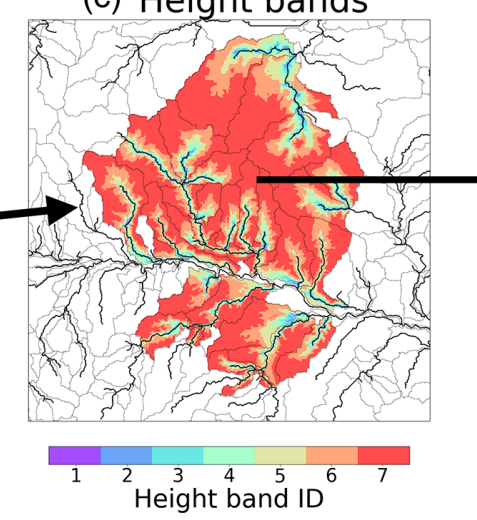

(d) Intra-band clusters

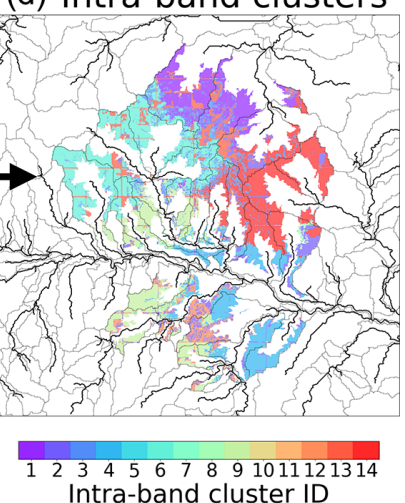

Figure 2. (a) The domain is split into 16 macroscale polygons, where each color identifies a polygon. (b) Each macroscale polygon is partitioned into 10 clusters of watersheds via $K$-means clustering. (c) The HAND data are used to discretize each cluster of watersheds from channel to ridge; this discretization allows us to assemble the channel and non-channel height bands. Finally, each of the height bands is split into intra-band clusters (d). The (c) and (d) methods are applied to all clusters of watersheds in (b) to assemble the final HRU map (e).

all $30 \mathrm{~m}$ pixels that belong to a given HRU to their closest channel. The travel times consider a constant velocity of the flow per grid cell (fixed to $0.1 \mathrm{~m} / \mathrm{s}$ in this study). Note that although the constant velocity parameter is set to $0.1 \mathrm{~m} / \mathrm{s}$, it is an HRU-specific parameter that can be modified by the user. The flow path across the landscape is computed via $\mathrm{d} 8$ flow direction. At each time step, the convolution of this histogram ( $\sim$ unit hydrograph) with the HRU runoff is used to compute the runoff from a given time step that reaches the channel at future time steps.

\subsection{Assembling the stream network and river reach cross-sectional profiles}

For each macroscale polygon, the river network is derived at a $30 \mathrm{~m}$ spatial resolution following the method described in Chaney et al. (2018). For each river reach, the channel width and bankfull depth are computed using the functional relationships derived for the contiguous United States described in Bieger et al. (2015). To minimize inconsistencies between reaches that belong to the same cluster of watersheds, the computed channel width and bankfull depths are averaged across all corresponding reaches. The cross-sectional profile for each reach (not cluster of watersheds) is learned by first extracting all the $30 \mathrm{~m}$ pixels in a given watershed; the profile follows the height band discretization from Sect. 2.3. The precomputed channel length is used to compute each section of the profile's width, given the corresponding height band's area within that reach. Because the spatial resolution of the $\operatorname{DEM}(30 \mathrm{~m})$ is much larger than many of the computed channel widths of the delineated streams $(\sim 1 \mathrm{~m})$, the additional fractions of each channel's colocated $30 \mathrm{~m}$ pixels that are not part of the channel are assigned to the height band right above the channel (i.e., the lowest element of the floodplain). Figure 3 shows an example of the computed profile for reach 122 in macroscale polygon 7. To avoid "step changes", the shown linear interpolation between the hand values of each height band is used when computing the cross-sectional area $A_{\mathrm{f}}$ and wetted perimeter $P_{\mathrm{f}}$ of a given channel's floodplain (as shown in Fig. 3). A different cross-sectional profile is made per reach in a given macroscale polygon. It is important to note that the routing scheme is run on the complete 


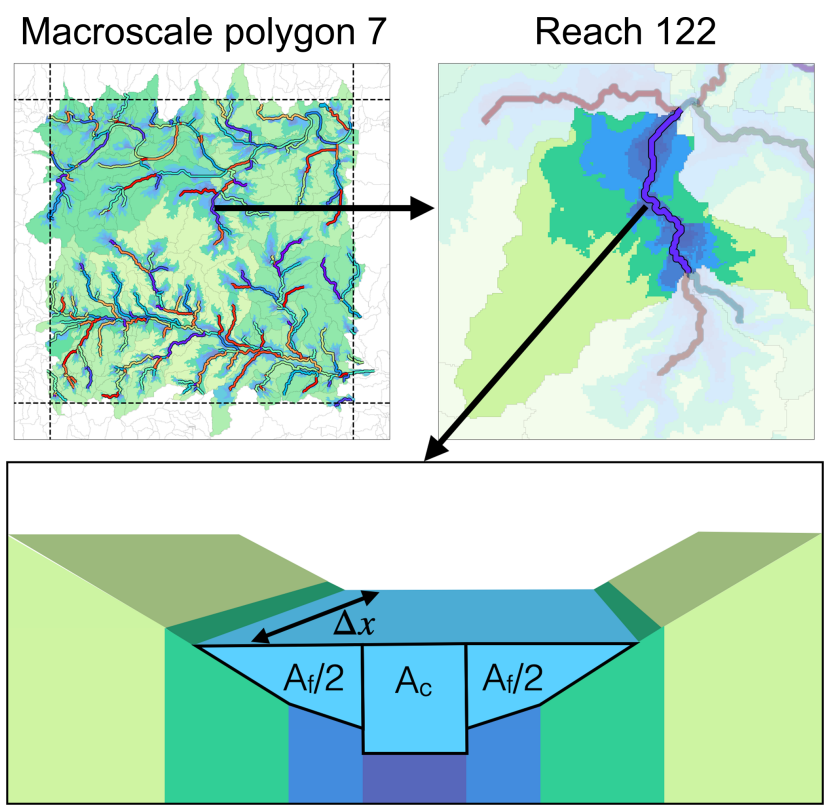

Figure 3. The illustration of a river reach in the domain. Using the HAND values, the river reaches are split into a channel (dark blue) and floodplain component (lighter blue and greens), where the floodplain component is a combination of the floodplains and hillslopes. Note that a few height bands are omitted in the diagram for simplicity. Similar profiles are assembled for each reach in each macroscale polygon.

DEM-derived sub-grid network of river reaches and not the clusters of watersheds (defined in Sect. 2.3).

\subsection{Two-way interaction: coupling of the land surface (HRUs) and the river reaches}

This section explains how the HRUs interact with the routing scheme's river reaches. After the river routing scheme (i.e., kinematic wave) is updated for a given time step (Fig. 4a), each reach's derived cross-sectional profile (see Sect. 2.5) is used to determine the inundation height over each of the height bands of that reach. This is done by effectively pouring the volume of water contained within the reach and calculating the inundation heights that correspond to a flat surface at the top of the river. To assemble the inundation heights for a given cluster of watersheds, the inundation heights per height band are averaged across all watersheds that belong to a given cluster of watersheds (Fig. 4b); these computed inundation heights are then equally distributed to their corresponding HRUs (Fig. 4c). The computed inundation height per HRU is then added to the following time step's update of Noah-MP as a constant flux at the soil surface (Fig. 4d). Water is not only able to infiltrate the soil in the HRU via Noah-MP, but it is also able to move laterally to another HRU via HydroBlocks' modeling of subsurface flow (see Sect. 2.2 for more details). The total column of runoff produced during the time step at the given HRU is set as the HRU's new inundation height. The difference between the old and new inundation heights are computed (Fig. 4e) and averaged up to the height band level (Fig. 4f). To determine the changes of inundation height at each reach (not cluster of watersheds), the computed differences in inundation heights at the cluster of watersheds level are scaled to the reach level. This is accomplished by multiplying the change in inundation height value by the ratio between the watershed's original inundation height per height band and its corresponding cluster of watersheds inundation height. These differences are then aggregated into a difference in cross-sectional area $\Delta A$ per watershed (Fig. 4g). Finally, this difference is divided by the model time step and added to the reach's source-sink term $S$ in the routing scheme (Fig. 4 h). Note that the sourcesink term also includes runoff originated from the land surface that is not inundated; this water arrives at the reach via the method described in Sect. 2.4. After updating the crosssectional area per reach via the river routing scheme, the twoway coupling begins again for the next time step (Fig. 4a).

\subsection{Model experiments}

A series of model experiments are run over the study's domain to evaluate the implementation of the two-way coupling between the land surface and the routing model within HydroBlocks. For all experiments, the model is run between 2015 and 2017 at an hourly time step. Furthermore, to parameterize and force HydroBlocks, a suite of high-resolution datasets are used, including the $1 \operatorname{arcsec}(\sim 30 \mathrm{~m})$ USGS national elevation dataset (Gesch et al., 2009), the $1 \mathrm{arcsec}$ $(\sim 30 \mathrm{~m})$ POLARIS soil properties database (Chaney et al., $2019)$, the $1 / 32^{\circ}(\sim 3 \mathrm{~km})$ Princeton CONUS Forcing (PCF) dataset (Pan et al., 2016) that provides meteorological forcing at $1 \mathrm{~h}$ temporal resolution, and the $1 \operatorname{arcsec}(\sim 30 \mathrm{~m}) \mathrm{Na}-$ tional Land Dover Database (Fry et al., 2011).

Boundary conditions are provided at the domain inlets of the Salt Fork Arkansas and Chikaskia rivers. Boundary conditions for the Arkansas river are not provided since it only covers a very small fraction of the domain in the northeast quadrant. For the Salt Fork Arkansas River, the discharge data from the Great Salt Plains Lake reservoir is used, and for the Chikaskia River, the USGS station at Corbin, Kansas, is used. The domain inlets do not exactly match up with the location of the gauges as the observed gauges are a few kilometers upstream. However, the benefits of including these data as boundary conditions appears to outweigh not using them.

For all experiments, the covariates used for identifying the clusters of watersheds are latitude, longitude, flow accumulation, and the natural logarithm of the flow accumulation area. The covariates used for the intra-band clusters (i.e., HRUs) are the $30 \mathrm{~m}$ resolution latitude, longitude, land cover, and percent clay. An overview of the set of experiments run are outlined below. 


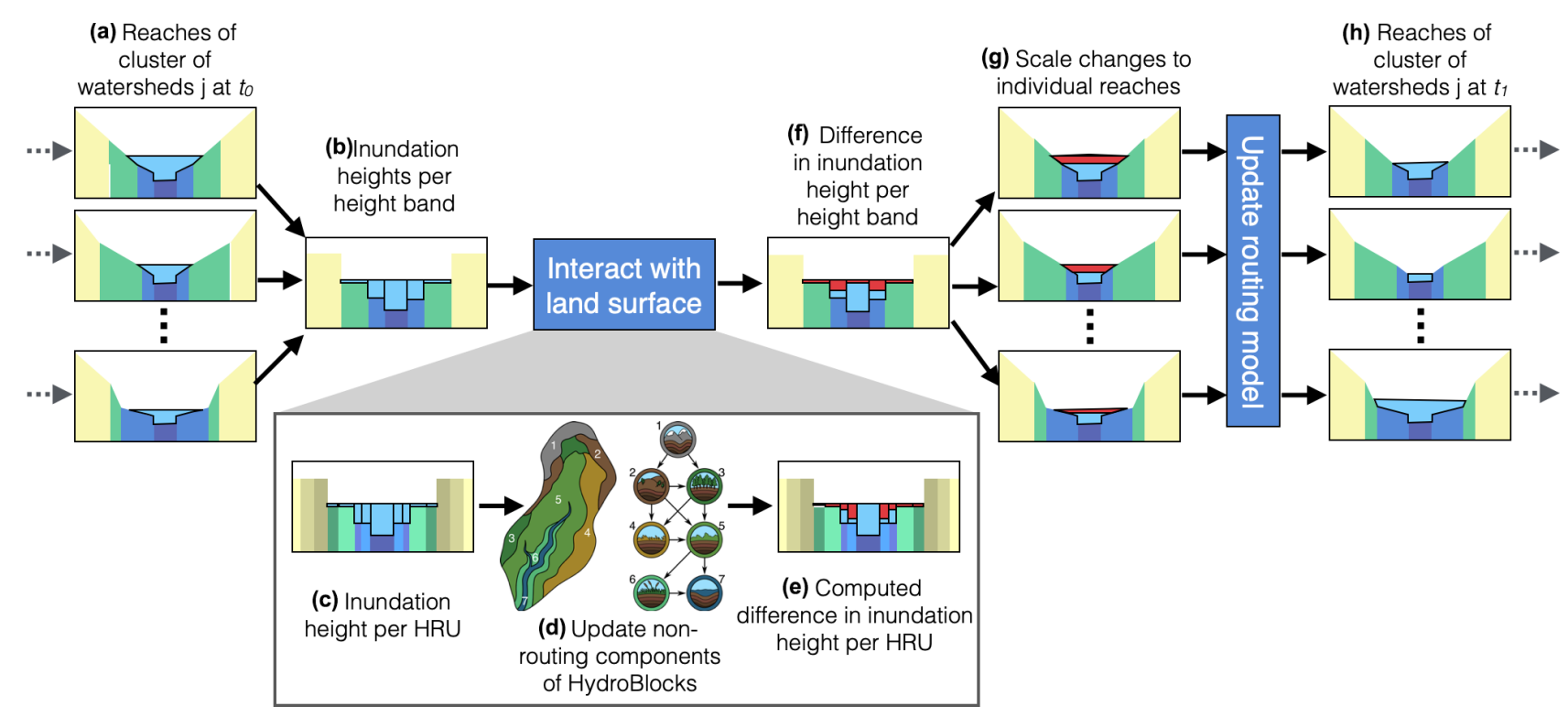

Figure 4. Floodplain inundation scheme implemented in HydroBlocks. After the routing module is updated for a given time step (a), each reach's computed cross-section profile is used to determine the inundation height over each of the height bands in a given reach. The inundation heights per height band are averaged across all watersheds in a given cluster of watersheds (b). These inundation heights are then equally distributed to their corresponding HRUs (c). To update the land surface model component, the computed inundation heights are added to the following time step as a constant flux at the soil surface to update the non-routing components of HydroBlocks (d). The difference between the old and new inundation heights are computed (e) and averaged back up to the height band level (f). The differences per height band at the cluster of watersheds level are first scaled to each watershed and then aggregated to compute the change in cross-sectional area $(\mathbf{g})$. This difference is then divided by the routing model time step and added to the routing module's source-sink term $S$ in the next iteration of the routing model (h).

Exploratory simulation. A baseline simulation is run to provide an initial overview of the features of the new model. The parameters of the introduced HRU generation scheme (see Sect. 2.3) are set to be $k=10, n=2$, and $p=5$.

Sensitivity to the two-way coupling. To evaluate the impact of the two-way interaction between the modeled rivers and the land surface, two model simulations are performed. For both simulations, the HRU generation scheme is the same as that used for the baseline experiment. The first one uses the default approach of not allowing the routing scheme to interact with the land surface, while the second enables the two-way connectivity scheme introduced in Sect. 2.6.

Convergence. Similar to the approach used in Chaney et al. (2018), nine different model experiments are run to evaluate how the HRU configuration parameters impact the model simulations. Simulations (a)-(c) focus on inter-watershed heterogeneity by increasing $k$ from 1 to 5 to 10 , while setting $p=1$ and $n=1000$. Simulations (d)-(f) focus on the discretization of the height bands by decreasing $n$ from 5 to 3 to 2 , while setting $p=1$ and $k=10$. Finally, simulations (g)-(i) focus on the role of intra-band heterogeneity by increasing the average number of intra-band clusters from 2 to 3 to 5 , while setting $n=2$ and $p=5$.

Sensitivity to routing model parameters. To determine the importance of the routing model parameters in HydroBlocks, following the approach used in Chaney et al. (2016a), a Sobol sensitivity analysis is performed. The Sobol sensitivity analysis (Sobol, 1993) is a method that decomposes the variance of the model output into contributions from each parameter (first-order index $S_{i}$ ) and its interactions with other parameters (total-effect index $S_{\mathrm{Ti}}$ ). The parameter ensemble used in the sensitivity analysis is assembled by sampling two ensembles of size $n_{\mathrm{s}}$ from the Sobol quasi-random sequence (Sobol, 1993) and then cross-sampled by holding one parameter fixed for a total of $n_{\mathrm{s}}\left(k_{\mathrm{s}}+2\right)$ parameter sets, where $k_{\mathrm{s}}$ is the number of parameters. In this study, $n_{\mathrm{s}}=64$ and $k_{\mathrm{s}}=5$, leading to a total of 448 parameter sets. Each parameter set is used to run a separate HydroBlocks simulations leading to 448 different ensemble members.

The modeled time series of domain-average latent heat flux, sensible heat flux, land surface temperature, and inundation height are then compared to the baseline coupled simulation via the root-mean squared error (RMSE). These calculated RMSE values are then used to compute the first-order sensitivity indices $\left(S_{i}\right)$ and the total-effect sensitivity indices $\left(S_{\mathrm{Ti}}\right)$. The model parameters used in the sensitivity analysis include the Manning's roughness coefficients for the channel and floodplains $\left(n_{\mathrm{c}}\right.$, and $\left.n_{\mathrm{f}}\right)$, the channel width $(w)$ the bankfull depth $(b)$, and the uniform overland flow velocity $(v)$. Given that each reach is assigned its own values for $n_{\mathrm{c}}$, 
$n_{\mathrm{f}}, w$, and $b$ when assembling the model over the domain, to minimize complexity a set of scalar multiplier parameters are used to scale the precomputed parameters of all reaches uniformly. The range for all the scalar multipliers is set to be $0.25-4$. This is not the case for the uniform overland flow velocity $(v)$, which is sampled in logarithmic space between $0.1-1 \mathrm{~m} / \mathrm{s}$ and assigned equally to each reach.

\section{Results}

\subsection{Exploratory simulation}

As an initial baseline simulation, the updated HydroBlocks model is run between 2015 and 2017 at an hourly resolution over the study domain using the HRU generation scheme parameters defined in Sect. 2.7. This section focuses on a simulated inundation event to provide a general understanding of the simulated land surface, routing scheme, and floodplain dynamics. Figure 5 shows the simulated inundated height at the peak of the flooding event on 11 August 2017 at 14:00 UTC. Note that only the central four $0.25^{\circ}$ grid cells in the domain are plotted for visual clarity. The time series of simulated discharge at four of the reaches in the area are shown as well. The inundation results show how flooding occurs primarily in the watersheds in the northwest and southeast grid cells. In all cases, the flooding appears to be a flash flood event, as the main river that traverses this section (Salt Fork Arkansas River) only barely floods. Closer inspection of the time series of reach 14 in macroscale polygon 6 and reach 8 in macroscale polygon 7 (both track the Salt Fork River) shows the role that the tributaries play in increasing the flow after reach 14 but before reach 8 . The latter secondary flood wave at both reaches most likely indicates regional influences provided by the boundary conditions into the domain upstream. Since the discharge of the Salt Fork River at the inlet to the domain originates from a reservoir, this most likely explains the dampened flood response.

To further investigate the impact that this flooding event has on the land surface, Fig. 6 shows the mapped simulated inundation height, root zone soil moisture, and latent heat flux over the same four central $0.25^{\circ}$ grid cells on 5 August 14:00 UTC, 11 August 14:00 UTC, and 14 August 14:00 UTC. The chosen time steps coincide with a dry period before the simulated event, right after the rain event, and a few days after the event. A brief description of the simulated states and fluxes for the three days is provided below.

- 5 August 2017 14:00 UTC. All rivers within the domain are within their banks with relatively low stage height within the channels. Not surprisingly, the root zone soil moisture is very low throughout the entire area, with the notable exceptions being the Salt Fork Arkansas River (west to east), the Chikaskia River (northeast), and the lakes throughout the region (note that, in the current implementation, lakes are modeled separately from the implemented river routing scheme). The tributaries throughout the region also have higher soil moisture due mostly to recharge from redistribution of runoff from the land surface via the river network. A similar story is evident in the mapped latent heat flux, with the only noticeable difference being the higher latent heat fluxes in the south of the domain.

- 11 August 2017 14:00 UTC. This time step falls within the flooding event. Several tributaries of the Salt Fork Arkansas River are flooding, and the stage height in the Salt Fork Arkansas River is appreciably higher than that only $6 \mathrm{~d}$ before. The flooding signal is immediately apparent in the root zone soil moisture, where the channel and adjacent HRUs are close to or at saturation. These differences are not as noticeable in the latent heat flux, most likely since the entire area is at or close to field capacity due to the widespread rain event, and thus the evapotranspiration is not constrained by soil moisture.

- 15 August 2017 14:00 UTC. The floodwaters have receded, and all rivers are again within their banks, although the stage height of the Salt Fork Arkansas River is still higher when compared to 8 August. Except for the channel HRUs, root zone soil moisture has decreased when compared to 11 August. However, the imprint of the flood event is still evident in the riparian zones.

The simulated events in Figs. 5 and 6 provide a first-order understanding of how all the pieces of the implemented land surface and routing scheme come together to directly impact surface fluxes, soil moisture, and flooding over the domain.

\subsection{Sensitivity to the two-way coupling}

Two different model experiments were run to further investigate the effect of the two-way coupling on the modeled states and fluxes. The first simulation is called "uncoupled", and it uses the default approach (i.e., not allowing the routing scheme to interact with the land surface). The second simulation is called "coupled", and it enables the connectivity scheme introduced in Sect. 2.6.

Figure 7 shows the difference in simulated annual mean sensible heat flux, latent heat flux, root zone soil moisture, and land surface temperature over the four central macroscale polygons in the domain. For each variable, the results are shown for both the uncoupled and the coupled simulations. These simulations would suggest that over this region, the local lateral flow of subsurface flow is only one of the contributors to sustaining the riparian zones (as represented in HydroBlocks). The redistribution of water via surface flow, flooding, and recharge also plays a key role in maintaining these ecosystems.

Figure 8 investigates the role of this coupling further by plotting the time series of the spatial mean and spatial standard deviation of sensible heat flux, inundation height, latent 


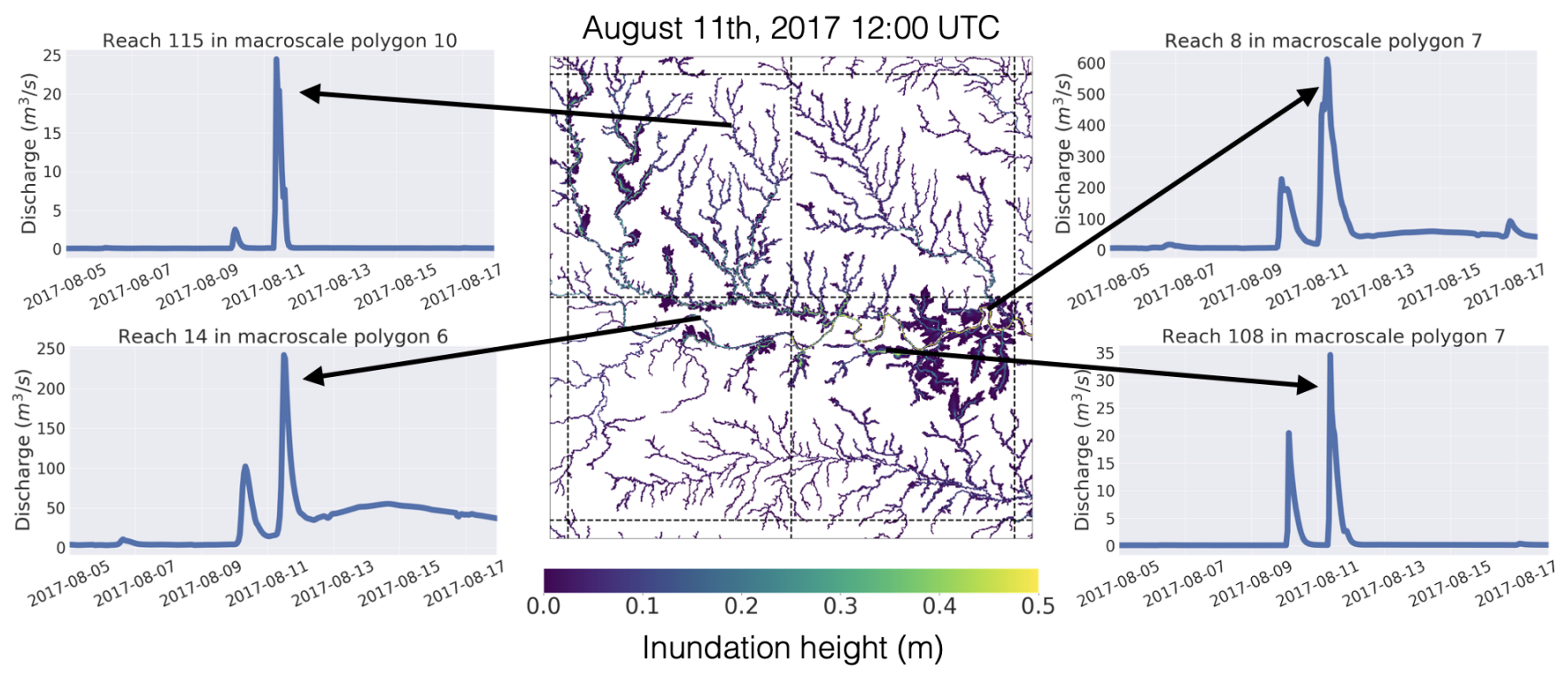

Figure 5. The center panel shows the simulated inundated height over the four central macroscale polygons in the study domain on 11 August 2017 at 12:00 UTC. The remaining four plots show the simulated discharge at four different reaches between 5 and 17 August. The arrows point to the time step on each time series that correspond to the mapped inundation height. Note that mapped inundation height is upscaled to a $100 \mathrm{~m}$ spatial resolution for visual clarity.
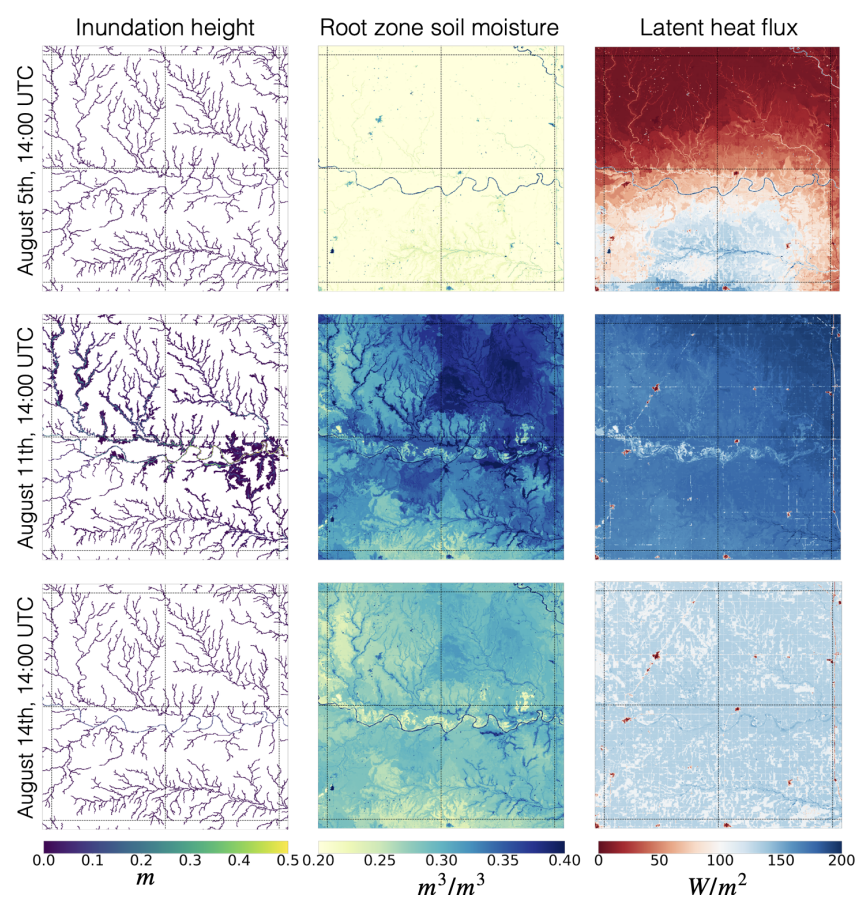

Figure 6. Mapped simulated inundation height, root zone soil moisture, and latent heat flux over the central four macroscale polygons in the study domain on three different time steps: 5 August 14:00 UTC, 11 August 14:00 UTC, and 14 August 14:00 UTC. The chosen time steps coincide with the event shown in Fig. 5 and show the area before, during, and after the flood event. heat flux, land surface temperature, and root zone soil moisture. In general, the results show how the coupling can lead to differences in both the spatial means and spatial standard deviations. The differences are more appreciable for the spatial standard deviation, as would be expected from the spatial maps from Fig. 7. While the relative change in the spatial mean between the two is on the order of $0.1 \%-2 \%$, the relative change in the spatial standard deviation can be around $20 \%-50 \%$ for variables such as latent heat flux and sensible heat flux. The differences are more extreme during the summer when the region is drier, and thus a recharge mechanism for the riparian zones will play a much more important role (as seen in Sect. 3.1). Overall, the results appear to show that adding a two-way coupling between the land surface and routing scheme will increase the macroscale evaporative fraction (and decrease the Bowen ratio).

\subsection{Convergence}

A convergence analysis was performed to determine how representative the reduced-order model representation in the updated HydroBlocks model is of the heterogeneity of the domain. More specifically, the model was run for increasingly complex HRU configurations. Simulations (a)-(c) focus on inter-watershed heterogeneity by increasing $k$ from 1 to 5 to 10 , while setting $p=1$ and $n=1000$. Simulations (d)-(f) focus on the discretization of the height bands by decreasing $n$ from 5 to 3 to 2 , while setting $p=1$ and $k=10$. Finally, simulations (g)-(i) focus on the role of intra-band heterogeneity by increasing the average number of intra-band clusters from 2 to 3 to 5 , while setting $n=2$ and $p=5$. 

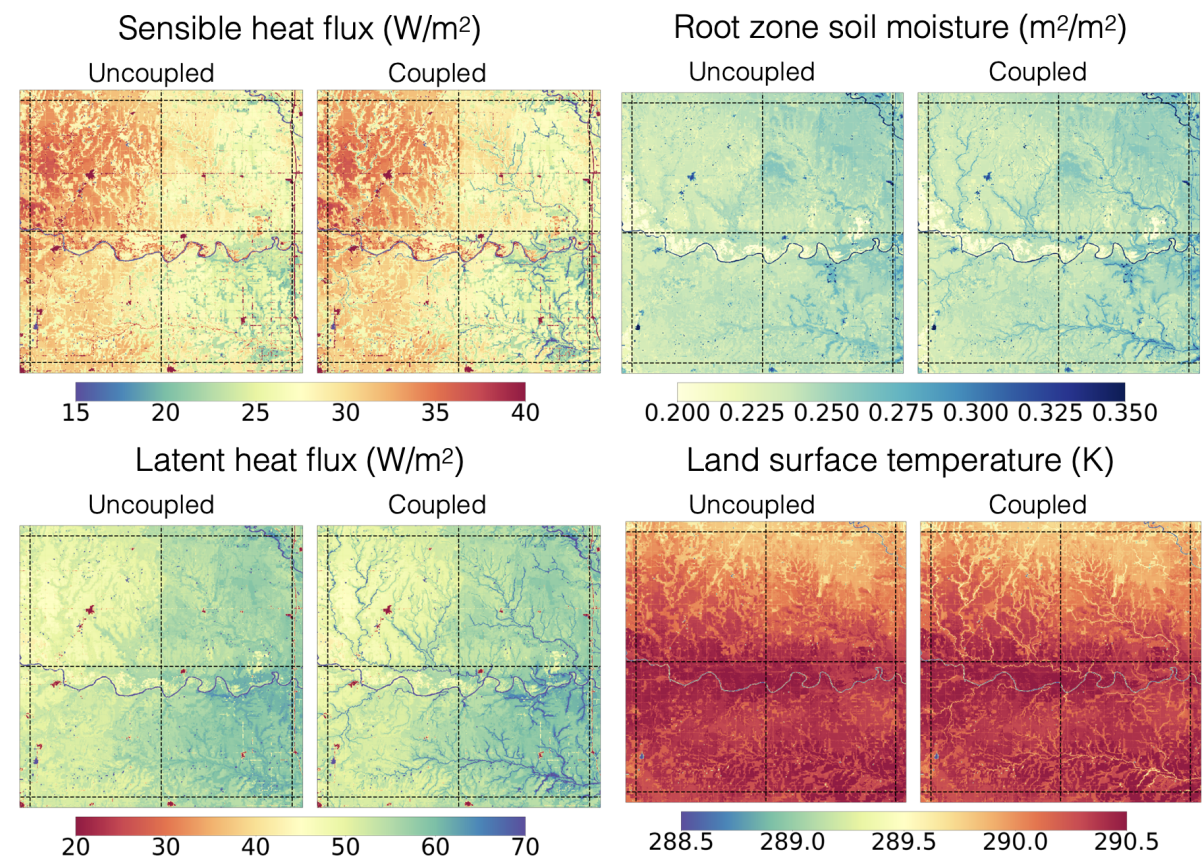

Figure 7. Annual mean sensible heat flux, latent heat flux, root zone soil moisture, and land surface temperature. The left column shows the results for the uncoupled simulations (i.e., the routing scheme does not interact with the land surface), while the right column shows the coupled simulations. Data were upscaled to a $100 \mathrm{~m}$ resolution for clarity.

Figure 9 illustrates how the increase in heterogeneity complexity impacts the fine-scale simulated sensible heat flux. More specifically, it shows the annual mean sensible heat flux over the domain. The explanation of the results below is split into understanding the role of each parameter:

a. Increasing the number of clusters of watersheds (increasing $k$ Fig. 9a-c). Initially, there are two HRUs represented per $0.25^{\circ}$ grid cell: one channel and one "floodplain". In this scenario, upon recharge of the floodplain, the characteristic inundation heights are effectively an area-weighted average between all of the inundation heights of all reaches (remember that the flow through each reach is still resolved in the routing scheme). Increasing the number of clusters of watersheds from 5 to 10 leads to differences in the connectivity between the rivers and the land surface. Increasing the number of clusters of watersheds leads to a separation between main channels and tributaries and thus a distinction between their interaction with their respective riparian zones. Increasing the number of clusters of watersheds also leads to an increase in spatial heterogeneity due to the ability to represent spatial differences in land cover and soil properties. For example, with 10 clusters of watersheds the southwest macroscale polygon is able to start to represent the urban settlements, such as the town of Enid.

b. Increasing the number of height bands (decreasing $n$; Fig. $9 \mathrm{~d}-\mathrm{f}$ ). As the $n$ parameter decreases (ratio between the area of a height band and its adjacent height band below it), the number of height bands increases. This enables a finer discretization at the channel-floodplain interface, which in turn leads to more realistic crosssectional profiles per reach and thus improved floodplain dynamics. When the number of height bands is too low, the inundation height that should correspond only to the region immediately adjacent to the channel is instead evenly distributed to a much larger area upslope, thus diffusing its influence on recharge of the riparian area.

c. Increasing the number of intra-band clusters (increasing $p$; Fig. 9g-i). The increase of intra-band clusters leads to a substantial increase in the heterogeneity within each macroscale polygon. The most noticeable difference is the emergence of the urban areas and the country roads and interstates (although these are not clearly visible at $1.0^{\circ}$ ). The other changes are driven by the separation between crops, grasslands, forests, and bare soil, as well as soil properties. Note how in this case the boundaries between the macroscale polygons effectively disappear.

Figure 10 formalizes the convergence analysis by showing how the temporal mean of the spatial mean and standard deviation of the plotted $30 \mathrm{~m}$ maps per $0.25^{\circ}$ varies as a function of the number of HRUs. For all cases, the largest differences in spatial means are across the different macroscale polygons, which illustrates the controlling role of climate 

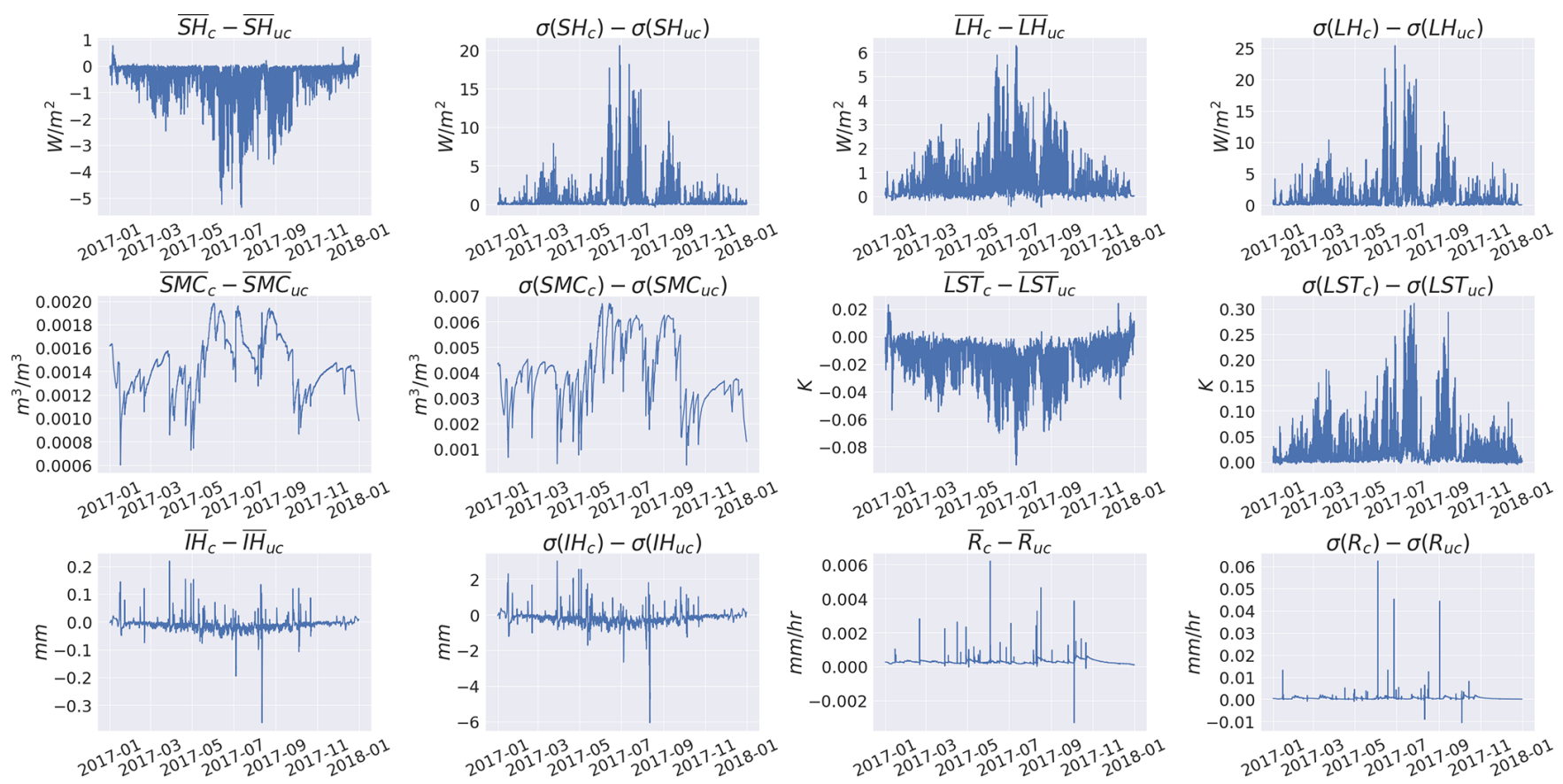

Figure 8. Temporal differences between the coupled and uncoupled simulations between 1 January 2017 and 31 December 2018 . The explored variables include the spatial mean $(\bar{X})$ and spatial standard deviation $(\sigma(X))$ of sensible heat flux $(\mathrm{SH})$, latent heat flux $(\mathrm{LH})$, root zone soil moisture (SMC), land surface temperature (LST), runoff $(R)$, and inundation height (IH).

and the model land characteristics in the macroscale polygon mean values for the majority of the variables. This can also be seen in Fig. 9, where the west to east gradient in precipitation-temperature-vegetation is readily apparent in the modeled sensible heat flux. For each case, the largest differences in the spatial mean occur when increasing the number of clusters of watersheds. For the spatial standard deviation (which can be interpreted as a metric of heterogeneity), the changes are more abrupt, with the largest changes occurring when increasing the number of clusters of watersheds. For all macroscale polygons in the domain, the convergence is relatively quick (although one could argue that root zone soil moisture has not yet converged). It is encouraging that all macroscale polygons follow similar paths and the use of 300-350 HRUs appears to be sufficient to adequately model the fine-scale features while maintaining computational efficiency - the 16 interconnected subdomains (i.e., macroscale polygons) take 5 min per year of simulation on 16 cores. This setup coincides with $k=10, n=2$, and $p=5$, which is the reasoning behind its use throughout the paper. It should be noted that this convergence analysis is non-exhaustive since it only looks at the predefined HMC parameter path configuration (see Sect. 2.7). For example, the role of the number of clusters of watersheds might be different if one starts by increasing the number of intra-band clusters instead of the number of clusters of watersheds. Work is ongoing among the co-authors to find the optimal path configuration to minimize the number of HRUs even further.

\subsection{Parameter sensitivity}

To assess the role of routing module parameters in the twoway coupling, a 448 member Sobol sensitivity analysis is run. This sensitivity experiment explores the role that the Manning's coefficients (channel and floodplain), the bankfull depth, the channel width, and uniform flow velocity have on the simulated macroscale states and fluxes. These results focus exclusively on 1-15 July 2017 since it covers a time period that shows a rapid wetting of the soil, followed by a prolonged drying period - ideal environmental conditions to explore the role of the two-way coupling.

Figure 11 illustrates the ensemble spread in the simulated spatial mean and spatial standard deviation for a suite of states and fluxes time series; the baseline uncoupled simulation that was used in Sect. 3.2 is also shown for comparison. The biggest difference between the uncoupled and coupled simulations happens primarily during the dry down period, where the latent heat spatial mean and spatial standard deviation are significantly enhanced with respect to the baseline simulation; the impact of the coupling on the spatial mean of most variables is negligible for almost all parameter sets. The parameter sensitivity plays an important role during the dry periods, with the flooding and recharge components playing a key role in these differences. As expected, the spread in the surface fluxes is most pronounced during the middle of the day since this is when available soil moisture will play the largest role in transpiration. Even though there is a clear sig- 


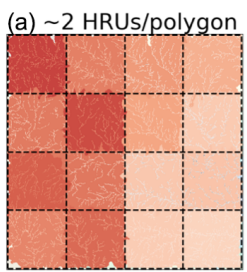

(d) 29 HRUs/polygon

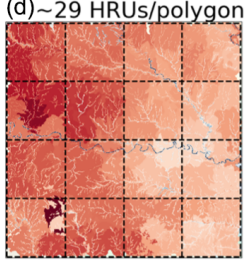

(g) 121 HRUs/polygon
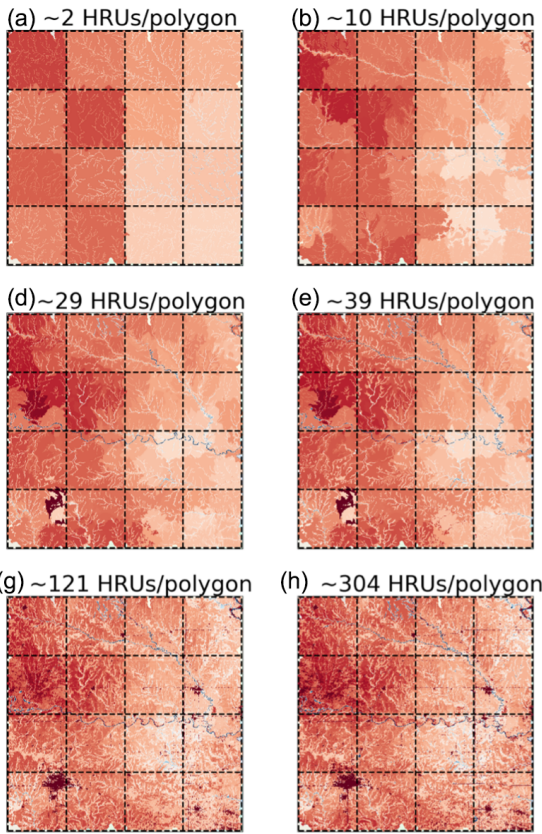

(e) 39 HRUs/polygon

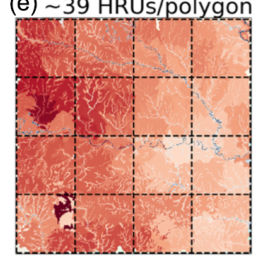

(h) 304 HRUs/polygo
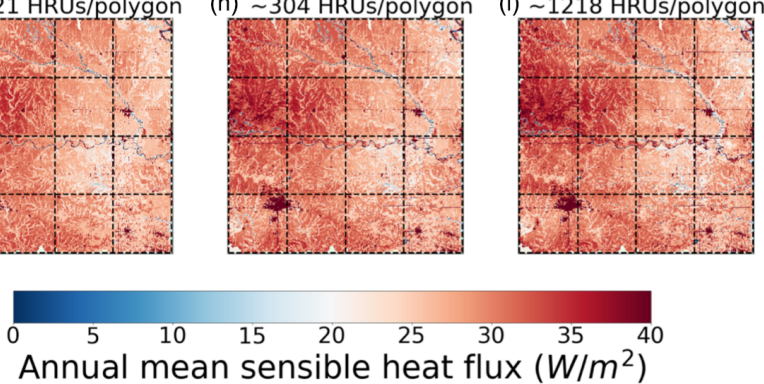

Figure 9. Simulated annual mean sensible heat flux over the $1.0^{\circ}$ SGP domain. Each panel shows the mean sensible heat flux from the different HydroBlocks simulations. Each simulation was run with different configurations of the revised hierarchical clustering algorithm. Simulations (a) $-(\mathbf{c})$ increase $k$ from 1 to 5 to 10 , while setting $p=1$ and $n=1000$; simulations (d)-(f) decrease $n$ from 5 to 3 to 2 , while setting $p=1$ and $k=10$; and simulations (g)-(i) increase the average number of intra-band clusters from 2 to 3 to 5 , while setting $n=2$ and $p=5$. The average number of HRUs per macroscale polygon is shown as the title of each panel (the number can differ per macroscale polygon).

nal in the sensitivity of the coupling to the parameters, the general role that the river plays is consistent for most parameter sets.

Figure 12 takes this sensitivity analysis a step further by exploring the role of each parameter. The results show that for sensible heat flux, latent heat flux, root-zone soil moisture, and land surface temperature, the channel width $(w)$ and channel bankfull depth $(b)$ play the largest role. In the case of the spatial mean of latent heat flux and sensible heat flux, there are important interactions of the channel width parameter $(w)$ with other parameters. In the case of runoff, the channel Manning's coefficient $\left(n_{\mathrm{f}}\right)$ plays the largest role with important secondary interactions most likely with the channel width $(w)$. Finally, the inundation height is almost primarily controlled by the channel Manning's coefficient $\left(n_{\mathrm{c}}\right)$. These results highlight the key role of channel geometry in determining the role of river networks on the macroscale fluxes and states; in practical terms, the role of channel width can be simply explained by the fact that a larger surface area of wa- ter will produce a larger latent heat flux over the domain. Although further analysis is necessary, this result is most likely irrespective of the two-way coupling. In the case of inundation height, the role of the channel Manning's coefficient is most likely simply due to how it defines the stage height of the channel (and thus inundation height); these results would most likely vary if the inundation height only factored in floodplain water. In all cases, the role of the floodplain Manning's coefficient is minimal indicating only a short period of time where there was inundated water on the floodplain. Finally, the role of the uniform overland flow velocity is small but not negligible for all cases.

\section{Discussion}

\subsection{Evaluating the two-way coupling parameterization}

The primary goal of this work is to develop and implement the two-way coupling parameterization within HydroBlocks. Although the results show the sensitivity of the model to the two-way coupling, it remains unclear if this parameterization improves the macroscale modeling of surface fluxes and inundation. Preliminary comparisons (not shown here) between domain-averaged in situ observations of surface fluxes and land surface temperature show negligible improvements; this is expected from Fig. 8, which shows minimal changes in spatial means between the coupled and uncoupled simulations. A more realistic evaluation of the parameterization should involve using observations that focus on the riparian zones and floodplains, which is where the impact of this two-way coupling will be most prominent. In the absence of new in situ measurements, one approach is to use highresolution remote sensing of land surface states and fluxes. More specifically, for land surface temperature one could use GOES $(\sim 2 \mathrm{~km})$, MODIS $(\sim 1 \mathrm{~km})$, and Ecostress $(\sim 100 \mathrm{~m})$. Other products that would be useful include field-scale evapotranspiration products derived from high-resolution satellite remote sensing data (e.g., Anderson et al., 2011). Beyond surface fluxes, the modeled inundation could be compared to remotely sensed maps of flood extent (e.g., Horritt and Bates, 2002) or against a hydrodynamic model (e.g., HECRAS; Brunner, 2010). All of these data would provide a more complete picture of the utility of the parameterization. Furthermore, the added value of this parameterization will most likely be larger in arid river basins such as the Niger and Nile river basins; basin-wide implementations of HydroBlocks over these regions would provide a more robust macroscale evaluation of the parameterization.

\subsection{Disconnect between clusters of watersheds and reach-based river routing}

One of the challenges of the two-way coupling implemented in HydroBlocks is the spatial disconnect between the hydrologic response units and the river reaches. This problem is 


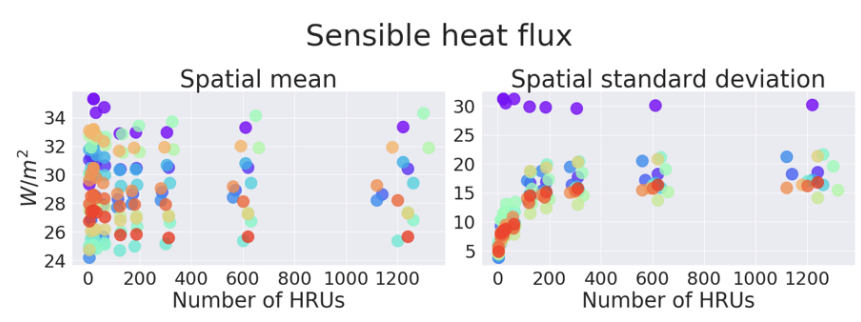

Latent heat flux
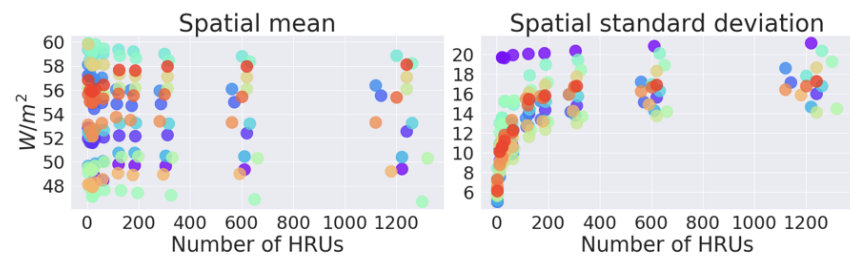

Root zone soil moisture
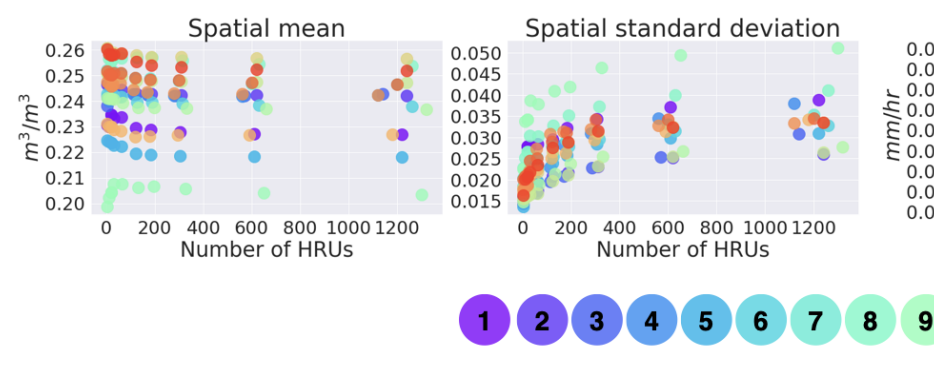

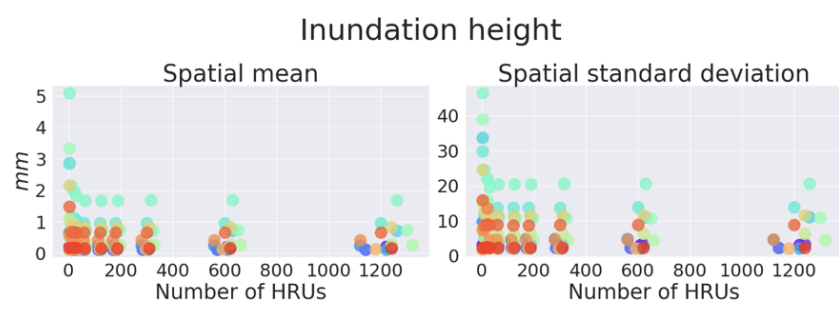

Skin temperature

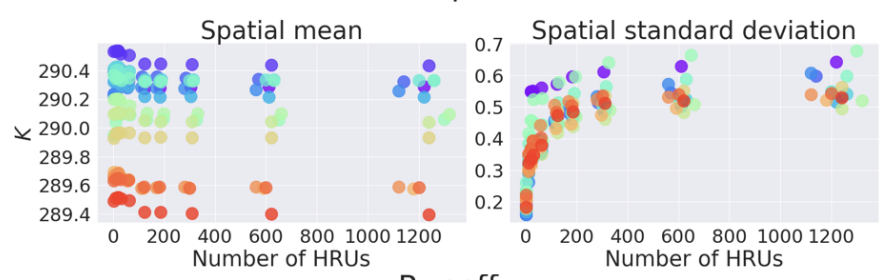

Runoff

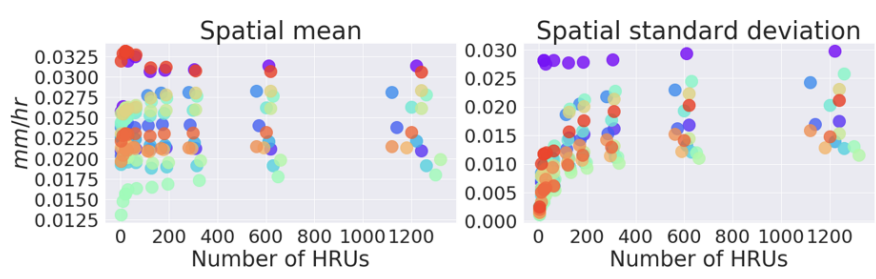

9

\section{Grid cell ID}

Figure 10. Convergence of annual mean of the spatial mean and spatial standard deviation of runoff, land surface temperature, inundation height, root zone soil moisture, latent heat flux, and sensible heat flux for the 9 different HRU configurations. Each color denotes a different macroscale polygon in the $1.0^{\circ} \mathrm{SGP}$ domain.

mostly due to the clustering of watersheds; each of the watersheds within a cluster of watersheds is assumed to behave similarly, even if their river reaches are higher-order or in a different region of a sub-polygon. The choice of cluster predictors is made to ameliorate these challenges. As can be seen in Fig. 2b, when assembling the clusters of watersheds, the watersheds are grouped based on their attributes. For watersheds that are along the main channel, using accumulation area as an attribute is able to separate these higherorder reaches from the lower ones; however, the existing coupling scheme still allows for water that is on the floodplain downstream within a given cluster of watersheds to be placed upstream at the beginning of the time step. This unrealistic "diffusive" intra-cluster redistribution is the primary limitation of this approach. For smaller-order streams, the grouping generally disregards the higher-order stream hierarchy. This means that lower-order streams are split between higher-order streams, which can lead to cross-basin redistribution. Future work should look into more appropriate ways to cluster these watersheds. One could imagine only allowing the clustering of watersheds to happen for lower-order reaches; the higher-order reaches could then be left as they are. This would effectively place the computational burden on the main channels of a given macroscale polygon while simplifying the tributaries. One could also only enable the two-way coupling for clusters of watersheds that are sufficiently physically consistent (e.g., main channels).

\subsection{Implementing dynamic lakes, reservoirs, and surface water abstraction}

The reach-based routing scheme explored in this study provides the scaffolding to model dynamic lakes and reservoirs. Assuming that the outflow positions of water bodies along the channel can be assigned to a model reach and that estimates of the bathymetry of the water bodies can be "burned" into the corresponding reach cross sections, this should be relatively straightforward to implement. The flooding component of the existing routing scheme enables a reach's corresponding valley to fill up and thus produce a first-order representation of the time-varying lake spatial coverage. Given that many lakes will cover multiple reaches, intra-reach water bodies will need to be included. Although an ad hoc parameterization could be used with the existing kinematic wave routing scheme, future updates should move towards a diffusive wave approach to be able to handle back flows. Finally, given the unavoidable split of water bodies among 

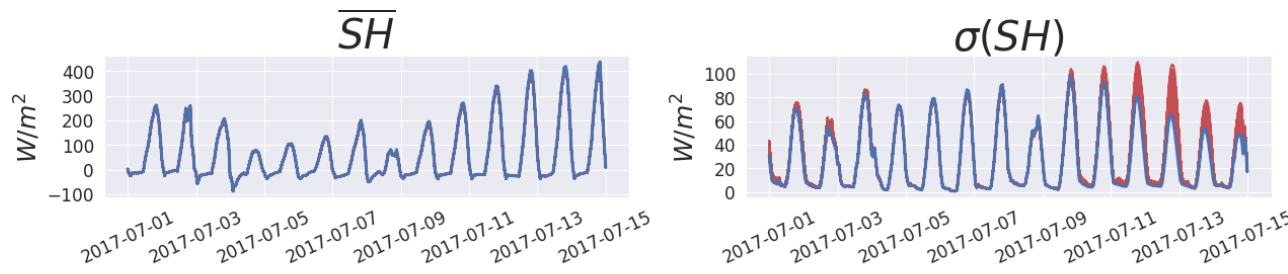

$\overline{L H}$

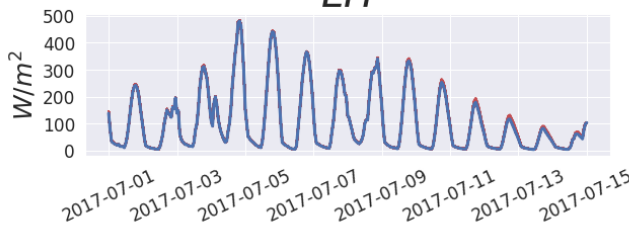

$\sigma(L H)$

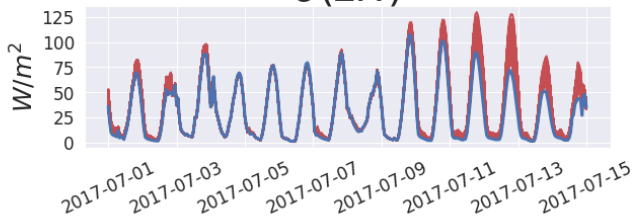

SMC
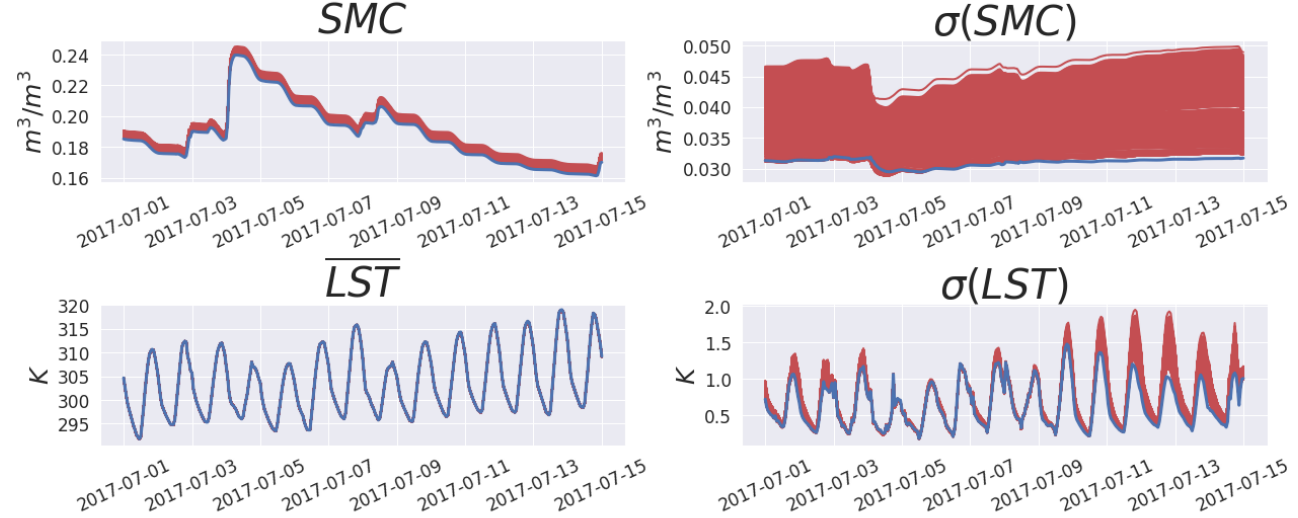

$\bar{R}$

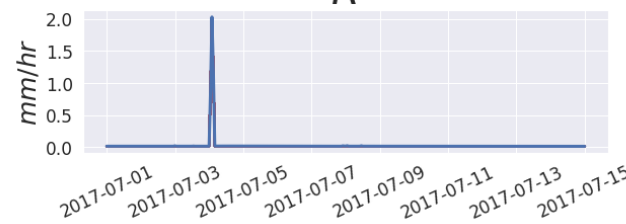

$\sigma(R)$
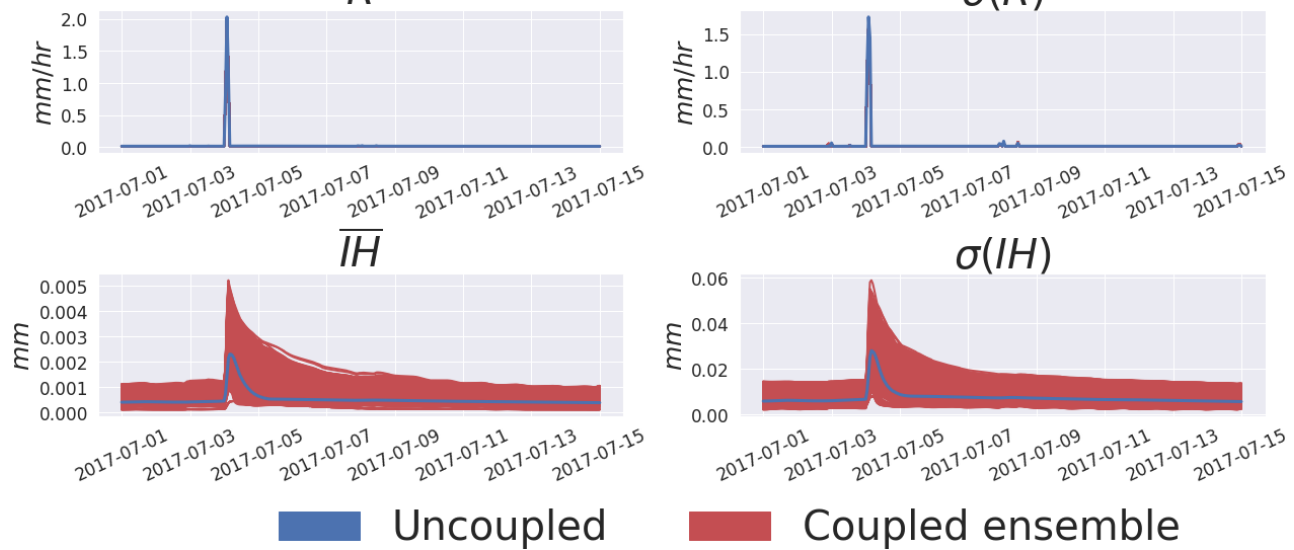

Figure 11. Ensemble spread from the Sobol sensitivity analysis of the coupled routing-land surface HydroBlocks model between 1 and 15 July 2017. The shown simulated variables include the spatial mean $(\bar{X})$ and spatial standard deviation $(\sigma(X))$ of sensible heat flux $(\mathrm{SH})$, latent heat flux (LH), root zone soil moisture (SMC), land surface temperature (LST), runoff $(R)$, and inundation height (IH). For comparison, the baseline uncoupled simulation is shown in blue.

macroscale polygons, careful attention will need to go to towards inter-macroscale polygon water bodies. However, there is no reason that the existing approach could not handle it; the only increase in computational burden would be to pass more information between macroscale polygons.

One of the primary motivations for implementing a coupling between a routing scheme and the land surface in HydroBlocks is to eventually enable the implementation of surface water management (e.g., irrigation from surface water abstraction and reservoir operations). The proposed implementation of lakes could be readily adapted for reservoirs. The primary difference is that the output flows would be controlled by operation rules instead of solely through lake storage. Furthermore, the reach-based implicit method used in this study would allow for surface water abstraction where each HRU that has irrigation can draw water from either the most accessible reservoir (as defined by the closest reach 

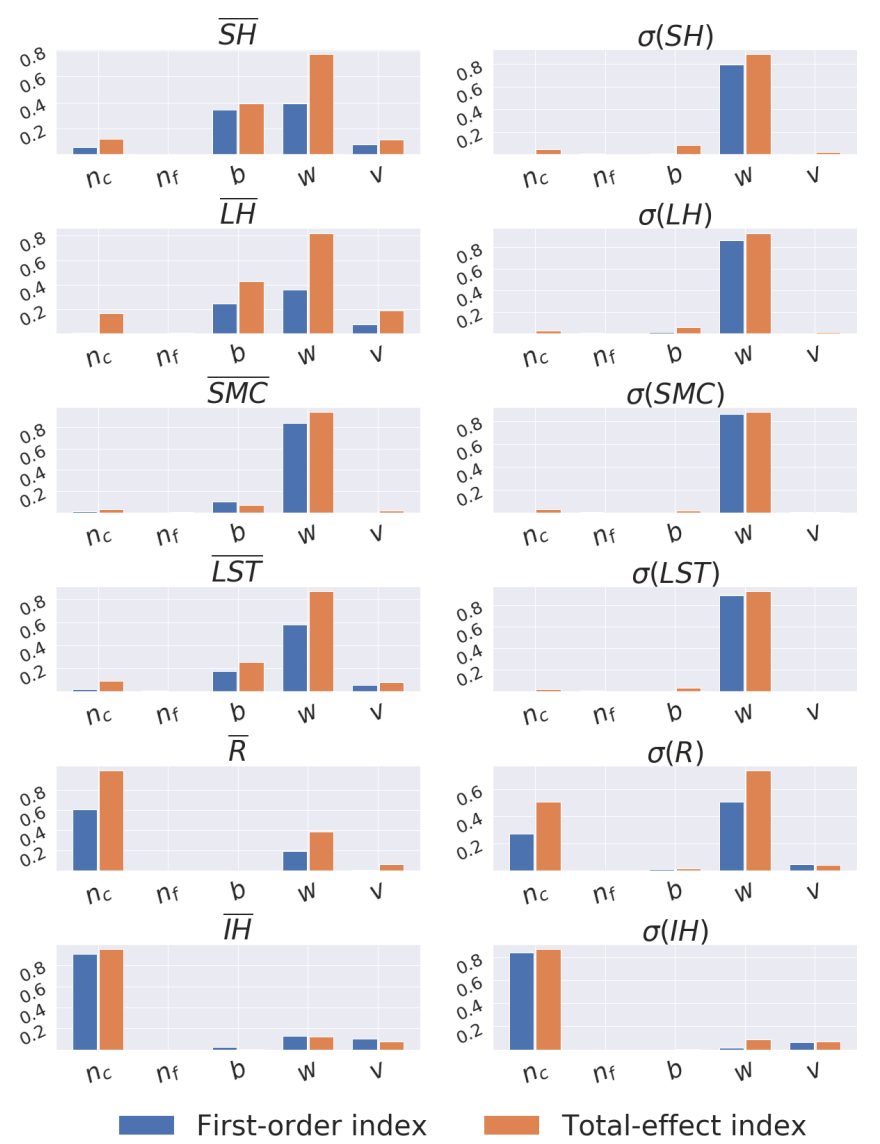

Figure 12. First-order $\left(S_{i}\right)$ and total-effect sensitivity $\left(S_{\mathrm{Ti}}\right)$ indices from the Sobol sensitivity analysis of the $n_{\mathrm{c}}$ (channel Manning's roughness coefficient), $n_{\mathrm{f}}$ (floodplain Manning's roughness coefficient), $b$ (channel bankfull depth), $w$ (channel width), and $v$ (uniform overland flow velocity) parameters in the HydroBlocks land surface model over the SGP site in Oklahoma. The explored simulated variables are the same as those in Fig. 11.

that is categorized as a reservoir), or directly from its closest channel.

\subsection{Improving the modeling of channel and floodplain dynamics}

Although the routing scheme implemented in HydroBlocks is able to represent the role of floodplains in the compound channel flow (see Sect. 2.4), there is still a lack of proper representation of the separation between channel and floodplain flow. Moving forward, an alternative would be to adapt the extended Saint-Venant equations used in HEC-RAS (Brunner, 2010). This approach solves the flow on both the channel and the floodplain by coupling two solutions of the SaintVenant equations via flow between the channel and floodplain. In addition, the implemented routing scheme uses the kinematic wave approximation of the Saint-Venant equations. However, this assumption is not suitable for many flat regions (e.g., Mississippi, Amazon). The simplest path for- ward appears to be the implementation of a diffusive assumption of the Saint-Venant equations. The added value of this approach would extend beyond a more realistic movement of water through the channel. It would also be useful as lakes and reservoirs are included in HydroBlocks, which will require the modeling of backwater effects. To address this problem, the current scheme should be replaced with a higher-order implicit scheme in future work. Finally, future efforts could also drop the uniform flow velocity assumption used to model overland flow along the hillslopes; this could be amended in a future version of HydroBlocks by calculating dynamic flow velocities (e.g., kinematic wave) when modeling HRU to channel overland flow (similar to MOSART, Li et al., 2013). However, given the relatively low sensitivity of the model to this parameter (see Fig. 12), the added value of dynamic overland flow velocities is unclear.

\subsection{Leveraging existing river network databases}

In this study, the river network was delineated directly from the National Elevation Dataset (NED) $30 \mathrm{~m}$ elevation dataset (Gesch et al., 2009). This was done to ensure the consistency between the river network and the DEM, which is necessary to form a rigorous coupling between the HRUs and the river reaches. As this approach is implemented over continental to global extents, this approach should be need be revisited. Over the United States, follow-up work should use the National Hydrography Dataset (NHD) (USGS, 2018). The NHD is a vector database that defines the spatial locations and connectivity of lakes, ponds, streams, rivers, canals, dams, and stream gages. Most importantly, this database includes the modified NED raster DEM, thus making a robust connection between the vector reaches and associated DEM. These data will also make it possible to consider endorheic basins and existing reservoirs and lakes. Over global extents, the MERIT hydro-vector database provides the clearest path forward (Lin et al., 2021). In any case, to be able to adequately use these data, there will be a need to further upgrade the existing routing scheme. As it currently is implemented, the existing approach is only able to couple a river with a channel width up to the fine-scale pixel length (e.g., $30 \mathrm{~m}$ ) to the land surface. Future implementations will amend this assumption to enable coarser rivers to interact with the floodplain.

\subsection{Optimizing macroscale polygon geometries for the two-way coupling scheme}

Preliminary results suggest that the current scheme has load balancing weaknesses on high-performance computing (HPC) when implemented over larger domains (e.g., the contiguous United States). This appears to be primarily due to the disparate number of river reaches between macroscale polygons. In other words, the domain decomposition (i.e., the geometries of the macroscale polygons) does not balance 
the sub-polygon river networks. Given the need for reaches to communicate between macroscale polygons, the most complex sub-grid river network slows down the solver over the entire domain. A promising path forward is to optimize the macroscale polygon geometries to enforce more balanced sub-polygon river network topologies. This is not a new challenge; existing macroscale vector routing schemes such as RAPID (David et al., 2016) and MizuRoute (Mizukami et al., 2021) have implemented optimal domain decomposition strategies. However, these domain decomposition approaches are not designed for a two-way coupling between HRUs and river reaches. When HRUs and their corresponding river reaches are on different computational cores in HydroBlocks, the computational slowdown due to messages passing between computational cores generally exceeds that due to load-balancing issues. Furthermore, the number of HRUs per macroscale polygon can vary; this is especially true if the number of HRUs is optimized per polygon. The mismatch between the number of reaches and HRUs, the need for the river reaches and HRUs of a given macroscale polygon to be on the same computational core (or at least same shared memory), and the unbalanced number of river reaches across the domain are the current roadblocks for ESM implementation that must be resolved moving forward.

\subsection{Reducing sub-polygon complexity: clustering lower-order river reaches}

Beyond optimizing macroscale polygon geometries to improve inter-polygon connectivity, there is a need to more adequately constrain the number of sub-polygon river reaches. Indeed, although the number of reaches per macroscale polygon in this study ( $\sim 400$ reaches per polygon) remains computationally tractable, preliminary results suggest that this is not always the case. This problem will be especially important in ESMs where the number of sub-polygon HRUs/tiles must be kept to under a few dozen; thus, the routing module would consume a significant portion of the land model's compute time. Furthermore, the increase in the number of reaches for coarser macroscale polygons would quickly add a significant computational burden (e.g., 2500-20000 reaches per $1.0^{\circ}$ grid cell). Therefore, moving forward, there is a need to simplify the sub-polygon networks. One approach being explored by the co-authors is to cluster the lower stream orders that fall within a given macroscale polygon; these river reaches can then be modeled as one. Given that the firstorder reaches usually take up more than half of the reaches of a macroscale polygon, if these were clustered and the numerical solver was adapted to handle this framework, this would reduce the number of reaches significantly. This approach could be applied to all tributaries while maintaining the sub-grid reaches of the main channels that traverse the macroscale polygon (similar to the approach used in MOSART, Li et al., 2013).

\section{Conclusions}

The existing lack of interconnectivity between the modeled river network and the land surface in ESMs leads to (1) oversimplified macroscale river networks (e.g., tributaries being mostly ignored), (2) no existing mechanism for sub-polygon river networks to interact with the land surface HRUs, (3) water moving through the river network not influencing the surface energy partitioning, and (4) sub-polygon irrigation and water management schemes that are spatially agnostic and rely mainly on the main channel. This study illustrates a path forward to address these persistent deficiencies in ESMs. This is accomplished by implementing a reachbased routing model in HydroBlocks and enabling a two-way coupling with the modeled hydrologic response units. The primary features of the novel river routing scheme include (1) each macroscale polygon being assigned its own fieldscale river network delineated from DEMs, (2) the fine-scale inlet-outlet reaches of the macroscale polygons being linked to assemble the continental river networks, (3) river dynamics being solved at the reach-level via an implicit solution of the kinematic wave simplification of the Saint-Venant equations, and (4) a two-way coupling being established between each cell's sub-grid tiles and the river network. The experiments run over the study domain illustrate the sensitivity of the land surface to recharge due to floodplain dynamics and the role that it can have on surface energy partitioning. Furthermore, the appreciable sensitivity of the model to reach characteristics reinforces the need for improved channel morphology parameterizations and datasets. Finally, the implemented scheme shows an appreciable impact on the modeled spatial heterogeneity (e.g., spatial variance) of surface fluxes and states; however, its influence on the macroscale spatial means is relatively small. In other words, although the two-way coupling parameterization offers potential to provide more realistic simulated multi-scale spatial patterns, its impact on improving the domain-average response appears to be limited and requires further evaluation.

Code and data availability. The model code and data used in this study are available at https://doi.org/10.5281/zenodo.4071692 (Chaney and Vergopolan, 2020) and https://doi.org/10.5281/zenodo.4070128 (Chaney, 2020).

Author contributions. NWC, NV, and CKF conceived the research. NWC and LTR developed and implemented the model. NWC led the writing of the paper, and NV, CKF, and LTR contributed to the writing.

Competing interests. The authors declare that they have no conflict of interest. 
Disclaimer. Publisher's note: Copernicus Publications remains neutral with regard to jurisdictional claims in published maps and institutional affiliations.

Acknowledgements. This study was supported by funding from NOAA grant NA19OAR4310241 (Parameterizing the effects of sub-grid land heterogeneity on the atmospheric boundary layer and convection: Implications for surface climate, variability and extremes) and NOAA grant NA19OAR4310244 (3D-Land Energy Exchanges: Harnessing High Resolution Terrestrial Information to Refine Atmosphere-to-Land interactions in Earth System Models).

We would like to dedicate this article to Peter Metcalfe, who passed away due to a climbing accident in 2018. Peter's help in developing the original HydroBlocks model was instrumental.

Financial support. This research has been supported by the National Oceanic and Atmospheric Administration, Climate Program Office (grant nos. NA19OAR4310241 and NA19OAR4310244).

Review statement. This paper was edited by Jeffrey Neal and reviewed by Dai Yamazaki and one anonymous referee.

\section{References}

Anderson, M. C., Kustas, W. P., Norman, J. M., Hain, C. R., Mecikalski, J. R., Schultz, L., González-Dugo, M. P., Cammalleri, C., d'Urso, G., Pimstein, A., and Gao, F.: Mapping daily evapotranspiration at field to continental scales using geostationary and polar orbiting satellite imagery, Hydrol. Earth Syst. Sci., 15, 223-239, https://doi.org/10.5194/hess-15-223-2011, 2011.

Avissar, R. and Pielke, R. A.: A Parameterization of Heterogeneous Land Surfaces for Atmospheric Numerical Models and Its Impact on Regional Meteorology, 117, 2113-2136, https://doi.org/10.1175/15200493(1989)117<2113:APOHLS>2.0.CO;2, 1989.

Beven, K., Cloke, H., Pappenberger, F., Lamb, R., and Hunter, N.: No Hyperresolution information and hyperresolution ignorance in modelling the hydrology of the land surface, Sci. China Earth Sci., 58, 25-35, 2015.

Bieger, K., Rathjens, H., Allen, P. M., and Arnold, J. G.: Development and Evaluation of Bankfull Hydraulic Geometry Relationships for the Physiographic Regions of the United States, J. Am. Water Res. Assoc., 51, 842-858, https://doi.org/10.1111/jawr.12282, 2015.

Bierkens, M. F. P., Bell, V., Burek, P., Chaney, N. W., Condon, L., Cédric, D., de Roo, A., Döll, P., Drost, N., Famiglietti, J. S., Flörke, M., Gochis, D., Houser, P., Hut, R. W., Keune, J., Kollet, S., Maxwell, R., Reager, J. T., Samaniego, L., Sudicky, E., Sutanudjaja, E. H., van de Giesen, N., Winsemius, H. C., and Wood, E. F.: Hyper-resolution global hydrological modeling: what's next, Hydrol. Process., 29, 310-320, 2014.

Bisht, G., Huang, M., Zhou, T., Chen, X., Dai, H., Hammond, G. E., Riley, W. J., Downs, J. L., Liu, Y., and Zachara, J. M.: Coupling a three-dimensional subsurface flow and transport model with a land surface model to simulate stream-aquiferland interactions (CP v1.0), Geosci. Model Dev., 10, 4539-4562, https://doi.org/10.5194/gmd-10-4539-2017, 2017.

Brunner, G.: HEC-RAS river analysis system, Hydraulic reference manual, Analysis System, Hydraulic Reference Manual, Version 1.0, Hydrologic Engineering Center Davis, CA, 1-790, 2010.

Chaney, N.: HydroBlocks SGP-ARM data, Zenodo [data set], https://doi.org/10.5281/zenodo.4070128, 2020.

Chaney, N. and Vergopolan, N.: chaneyn/HydroBlocks: HBrouting_Oct2020, Zenodo [code] https://doi.org/10.5281/zenodo.4071692, 2020.

Chaney, N. W., Herman, J. D., Ek, M. B., and Wood, E. F.: Deriving global parameter estimates for the Noah land surface model using FLUXNET and machine learning, J. Geophys. Res.-Atmos., 121, 13-218, https://doi.org/10.1002/2016JD024821, 2016a.

Chaney, N. W., Metcalfe, P., and Wood, E. F.: HydroBlocks: a field-scale resolving land surface model for application over continental extents, Hydrol. Process., 30, 3543-3559, https://doi.org/10.1002/hyp.10891, 2016b.

Chaney, N. W., Van Huijgevoort, M. H. J., Shevliakova, E., Malyshev, S., Milly, P. C. D., Gauthier, P. P. G., and Sulman, B. N.: Harnessing big data to rethink land heterogeneity in Earth system models, Hydrol. Earth Syst. Sci., 22, 3311-3330, https://doi.org/10.5194/hess-22-3311-2018, 2018.

Chaney, N. W., Minasny, B., Herman, J. D., Nauman, T. W., Brungard, C. W., Morgan, C. L. S., McBratney, A. B., Wood, E. F., and Yimam, Y.: POLARIS Soil Properties: 30-m Probabilistic Maps of Soil Properties Over the Contiguous United States, Water Resour. Res., 55, 2916-2938, https://doi.org/10.1029/2018WR022797, 2019.

Clark, M. P., Nijssen, B., Lundquist, J., Kavetski, D., Rupp, D., Woods, R., Gutmann, E., Wood, A., Brekke, L., Arnold, J., Gochis, D., and Rasmussen, R.: A unified approach to processbased hydrologic modeling, Part 1: Modeling concept, Water Resour. Res., 51, 2498-2514, 2015a.

Clark, M. P., Fan, Y., Lawrence, D. M., Adam, J. C., Bolster, D., Gochis, D. J., Hooper, R. P., Kumar, M., Leung, L. R., Mackay, D. S., Maxwell, R. M., Shen, C., Swenson, S. C., and Zeng, X.: Improving the representation of hydrologic processes in Earth System Models, Water Resour. Res., 51, 5929-5956, https://doi.org/10.1002/2015WR017096, 2015b.

David, C. H., Maidment, D. R., Niu, G. Y., Yang, Z. L., Habets, F., and Eijkhout, V.: River network routing on the NHDPlus dataset, J. Hydrometeorol., 12, 913-934, https://doi.org/10.1175/2011JHM1345.1, 2011.

David, C. H., Famiglietti, J. S., Yang, Z.-L., Habets, F., and Maidment, D. R.: A decade of RAPID-Reflections on the development of an open source geoscience code, Earth Space Sci., 3, 226-244, https://doi.org/10.1002/2015EA000142, 2016.

Fan, Y., Clark, M., Lawrence, D. M., Swenson, S., Band, L. E., Brantley, S. L., Brooks, P. D., Dietrich, W. E., Flores, A., Grant, G., Kirchner, J. W., Mackay, D. S., McDonnell, J. J., Milly, P. C. D., Sullivan, P. L., Tague, C., Ajami, H., Chaney, N., Hartmann, A., Hazenberg, P., McNamara, J., Pelletier, J., Perket, J., Rouholahnejad-Freund, E., Wagener, T., Zeng, X., Beighley, E., Buzan, J., Huang, M., Livneh, B., Mohanty, B. P., Nijssen, B., Safeeq, M., Shen, C., Verseveld, W., Volk, J., and Yamazaki, D.: Hillslope hydrology in global change research and Earth system modeling, Water Resour. Res., 55, 1737-1772, 2019. 
Fry, J., Xian, G., Jin, S., Dewitz, J., Homer, C., Yang, L., Barnes, C., Herold, N., and Wickham, J.: Completion of the $2006 \mathrm{Na}-$ tional Land Cover Database for the conterminous United States, Photogramm. Eng. Remote Sens., 77, 858-864, 2011.

Gesch, D., Evans, G., Mauck, J., Hutchinson, J., and Carswell Jr., W. J.: The National Map - Elevation: U.S. Geological Survey fact sheet, Chicago, 2009.

Helton, A. M., Poole, G. C., Payn, R. A., Izurieta, C., and Stanford, J. A.: Relative influences of the river channel, floodplain surface, and alluvial aquifer on simulated hydrologic residence time in a montane river floodplain, Geomorphology, 205, 17-26, https://doi.org/10.1016/j.geomorph.2012.01.004, 2012.

Horritt, M. S. and Bates, P. D.: Evaluation of 1D and 2D numerical models for predicting river flood inundation, J. Hydrol., 268, 8799, https://doi.org/10.1016/S0022-1694(02)00121-X, 2002.

Jacovkis, P. M. and Tabak, E. G.: A kinematic wave model for rivers with flood plains and other irregular geometries, Mathemat. Comput. Model., 24, 1-21, https://doi.org/10.1016/S08957177(96)00169-0, 1996.

Jones, N. E. and Schmidt, B. J.: Tributary effects in rivers: Interactions of spatial scale, network structure, and landscape characteristics, Can. J. Fish. Aquat. Sci., 74, 503-510, https://doi.org/10.1139/cjfas-2015-0493, 2017.

Koster, R. D. and Suarez, M. J.: Modeling the Land Surface Boundary in Climate Models as a Composite of Independent Vegetation Stands, J. Geophys. Res.-Atmos., 97, 2697-2715, 1992.

Li, H., Wigmosta, M. S., Wu, H., Huang, M., Ke, Y., Coleman, A. M., and Leung, L. R.: A physically based runoff routing model for land surface and earth system models, J. Hydrometeorol., 14, 808-828, https://doi.org/10.1175/JHM-D-12-015.1, 2013.

Lin, P., Pan, M., Wood, E. F., Yamazaki, D., and Allen, G. H.: A new vector-based global river network dataset accounting for variable drainage density, Sci. data, 8, 1-9, https://doi.org/10.1038/s41597-021-00819-9, 2021.

Lohmann, D., Nolte-Holube, R., and Raschke, E.: A large-scale horizontal horizontal routing model to be coupled to land surface parameterization schemes, Tellus A, 48, 708-721, 1996.

Mizukami, N., Clark, M. P., Sampson, K., Nijssen, B., Mao, Y., McMillan, H., Viger, R. J., Markstrom, S. L., Hay, L. E., Woods, R., Arnold, J. R., and Brekke, L. D.: mizuRoute version 1: a river network routing tool for a continental domain water resources applications, Geosci. Model Dev., 9, 2223-2238, https://doi.org/10.5194/gmd-9-2223-2016, 2016.

Mizukami, N., Clark, M. P., Gharari, S., Kluzek, E., Pan, M., Lin, P., Beck, H. E., and Yamazaki, D.: A vector-based river routing model for Earth System Models: Parallelization and global applications, J. Adv. Model. Earth Syst., 13, e2020MS002434, https://doi.org/10.1029/2020ms002434, 2021.

Newman, A. J., Clark, M. P., Winstral, A., Marks, D., and Seyfried, M.: The Use of Similarity Concepts to Represent Subgrid Variability in Land Surface Models: Case Study in a SnowmeltDominated Watershed, J. Hydrometeorol., 15, 1717-1738, 2014.

Niu, G.-Y., Yang, Z.-L., Mitchel, K. E., Chen, F., Ek, M., Barlage, M., Kumar, A., Manning, K., Niyogi, D., Rosero, E., Tewari, M., and Xia, Y.: The community Noah land surface model with multiparameterization options (NOAH-MP): 1. Model description and evaluation with local-scale measurements, J. Geophys. Res.-Atmos., 116, D12, https://doi.org/10.1029/2010JD015139, 2011.
Nobre, A. D., Cuartas, L. A., Hodnett, M., Rennó, C. D. Rodrigues, G., Silveira, A., Waterloo, M., and Saleska, S.: Height Above the Nearest Drainage - a hydrologically relevant new terrain model, J. Hydrol., 404, 13-29, https://doi.org/10.1016/j.jhydrol.2011.03.051, 2011.

Oki, T. and Sud, Y. C.: Design of Total Runoff Integrating Pathways (TRIP) - A Global River Channel Network, Earth Int., 2, 1-37, https://doi.org/10.1175/10873562(1998)002<0001:dotrip>2.3.co;2, 1998.

Pan, M., Cai, X., Chaney, N. W., Entekhabi, D., and Wood, E. F.: An initial assessment of SMAP soil moisture retrievals using high-resolution model simulations and in situ observations, Geophys. Res. Lett., 43, 9662-9668, https://doi.org/10.1002/2016GL069964, 2016.

Pappenberger, F., Cloke, H. L., Balsamo, G., Ngo-Duc, T., and Oki, T.: Global runoff routing with the hydrological component of the ECMWF NWP system, Int. J. Climatol., 30, 2155-2174, https://doi.org/10.1002/joc.2028, 2010.

Pokhrel, Y. N., Koirala, S., Yeh, P. J. F., Hanasaki, N., Longuevergne, L., Kanae, S., and Oki, T.: Incorporation of groundwater pumping in a global Land Surface Model with the representation of human impacts, Water Resour. Res., 51, 78-96, https://doi.org/10.1002/2014WR015602, 2015.

Pokhrel, Y. N., Hanasaki, N., Wada, Y., and Kim, H.: Recent progresses in incorporating human land-water management into global land surface models toward their integration into Earth system models, Wiley Int. Rev.-Water, 3, 548-574, https://doi.org/10.1002/wat2.1150, 2016.

Reichle, R. H. and Koster, R. D.: Bias reduction in short records of satellite soil moisture, Geophys. Res. Lett., 31, 19, https://doi.org/10.1029/2004GL020938, 2004.

Rice, S. P.: Tributary connectivity, confluence aggradation and network biodiversity, J. Geomorph., 277, 6-16, https://doi.org/10.1016/j.geomorph.2016.03.027, 2017.

Shaad, K. and Di Baldassarre, G.: Evolution of river-routing schemes in macro-scale models and their potential for watershed management, Hydrol. Sci. J., 63, 1062-1077, https://doi.org/10.1080/02626667.2018.1473871, 2018.

Shen, C., Riley, W. J., Smithgall, K. R., Melack, J. M., and Fang, K.: The fan of influence of streams and channel feedbacks to simulated land surface water and carbon dynamics, Water Resour. Res., 52, 880-902, https://doi.org/10.1002/2015WR018086, 2016.

Sheng, M., Lei, H., Jiao, Y., and Yang, D.: Evaluation of the Runoff and River Routing Schemes in the Community Land Model of the Yellow River Basin, J. Adv. Model. Earth Syst., 9, 29933018, https://doi.org/10.1002/2017MS001026, 2017.

Sobol, I. M.: Sensitivity estimates for nonlinear mathematical models, Math. Model. Comput. Exp., 1, 407-417, 1993.

Subin, Z. M., Milly, P. C. D., Sulman, B. N., Malyshev, S., and Shevliakova, E.: Resolving terrestrial ecosystem processes along a subgrid topographic gradient for an earth-system model, Hydrol. Earth Syst. Sci. Discuss., 11, 8443-8492, https://doi.org/10.5194/hessd-11-8443-2014, 2014.

Swanson, B. J. and Meyer, G.: Tributary confluences and discontinuities in channel form and sediment texture: Rio Chama, Earth Surf. Process. Land., 39, 1927-1943, https://doi.org/10.1002/esp.3586, 2014. 
Swenson, S. C., Clark, M., Fan, Y., Lawrence, D. M., and Perket, J.: Representing Intrahillslope Lateral Subsurface Flow in the Community Land Model, J. Adv. Model. Earth Syst., 11, 4044-4065, https://doi.org/10.1029/2019MS001833, 2019.

USGS: National Hydrography Dataset, available at: https://www.usgs.gov/core-science-systems/ (last access: 15 July 2020), 2019.

Vergopolan, N., Chaney, N. W., Beck, H. E., Pan, M., Sheffield, J., Chan, S., and Wood, E. F.: Combining hyper-resolution land surface modeling with SMAP brightness temperatures to obtain 30m soil moisture estimates, Remote Sens. Environ., 242, 111740, https://doi.org/10.1016/j.rse.2020.111740, 2020.

Voisin, N., Hejazi, M. I., Leung, L. R., Liu, L., Huang, M., Li, H.-Y., and Tesfa, T.: Effects of spatially distributed sectoral water management on the redistribution of water resources in an integrated water model, Water Resour. Res., 53, 4253-4270, https://doi.org/10.1002/2016WR019767, 2017.
Wood, E. F., Roundy, J. K., Troy, T. J., Beek, L. P. H. van, Bierkens, M. F. P., Blyth, E., Roo, A. de, Döll, P., Ek, M., Famiglietti, J., Gochis, D., Giesen, N. van de, Houser, P., Jaffé, P. R., Kollet, S., Lehner, B., Lettenmaier, D. P., Peters-Lidard, C., Sivapalan, M., Sheffield, J., Wade, A., and Whitehead, P.: Hyperresolution global land surface modeling: Meeting a grand challenge for monitoring Earth's terrestrial water, Water Resour. Res., 47, 1-10, https://doi.org/10.1080/00397910600978218, 2011.

Yamazaki, D., Kanae, S., Kim, H., and Oki, T.: A physically based description of floodplain inundation dynamics in a global river routing model, Water Resour. Res., 47, W04501, https://doi.org/10.1029/2010WR009726, 2011.

Zampieri, M., Serpetzoglou, E., Anagnostou, E. N., Nikolopoulos, E. I., and Papadopoulos, A.: Improving the representation of river-groundwater interactions in land surface modeling at the regional scale: Observational evidence and parameterization applied in the Community Land Model, J. Hydrol., 420, 72-86, https://doi.org/10.1016/j.jhydrol.2011.11.041, 2011. 